This is the peer reviewed version of the following article: Pérez-Vázquez, J., Veiga, A., Prado, G., Sardina, F., \& Paleo, M. (2012). Enantioselective Annulation Reactions of Bisenolates Prepared Through Dearomatization Reactions of Aromatic and Heteroaromatic Diesters. European Journal Of Organic Chemistry, 2012(5), 975-987, which has been published in final form at https:// doi.org/10.1002/ejoc.201101427.

This article may be used for non-commercial purposes in accordance with Wiley Terms and Conditions for Use of Self-Archived Versions 


\title{
Enantioselective Annulation Reactions of Bis-enolates Prepared through Dearomatization Reactions of Aromatic and Heteroaromatic Diesters
}

\author{
Jaime Pérez-Vázquez, Alberte X. Veiga, Gustavo Prado, F. Javier Sardina* and M. Rita Paleo*[a]
}

Keywords: Dearomatization-alkylation / Stanna-Brook / Bis-enolate / Annulation / Enantioselective alkylation

A one-pot, enantioselective strategy for the dearomatizationannulation of aromatic diesters to give a range of highly functionalized polycyclic molecules with excellent enantioselectivities is presented. This methodology is based on the reaction of bis-enolates, prepared by treating aromatic diesters with trialkyltin lithium reagents, a process which involves a stannaBrook rearrangement, with 1, $\omega$-dihaloalkanes and other biselectrophiles.
We have also developed experimental conditions for performing these reactions with substoichiometric amounts of the required tin reagent, by in situ recycling $\mathrm{Me}_{6} \mathrm{Sn}_{2}$ into $\mathrm{Me}_{3} \mathrm{SnLi}$ with excess lithium metal, and provide a study of the scope and limitations of this synthetic methodology. [a] Departamento de Química Orgánica and Centro Singular de Investigación en Química Biológica y Materiales Moleculares Universidad de Santiago de Compostela

Đ 15782 Santiago de Compostela, Spain Fax: +34-981595012

E-mail: javier.sardina@usc.es, rita.paleo@usc.es

Supporting information for this article is available on the WWW under http://www.eurjoc.org/.

\section{Introduction}

Synthetic methodologies based on the use of tandem dearomatization ${ }^{[1]}$-alkylation reactions hold great potential for the preparation of complex organic structures. ${ }^{[2]}$ Several of the general methods available to dearomatize arene compounds, such as nucleophilic addition to aromatic rings, ${ }^{[1 \mathrm{a}, 3]}$ oxidation, ${ }^{[4]}$ reduction, ${ }^{[5]}$ and transition-metal-mediated processes ${ }^{[6]}$ (along with some other reactions of narrower scope ${ }^{[7]}$ ) have been developed into highly useful tandem dearomatization-alkylation protocols. To further increase the synthetic value of this type of approaches, several enantioselective variants of some of these transformations have been developed. ${ }^{[2,4]}$ Worthy of note in this particular respect are the alkylative-dearomatization reactions of phenols ${ }^{[2 \mathrm{~d}-\mathrm{e}]}$ and anilines. $^{[2 \mathrm{f}]}$

Despite of their great potential, there is a certain scarcity of synthetic tandem procedures based on reductive dearomatization reactions coupled to alkylative processes. This is surprising considering that these reductive dearomatizations provide an efficient route to highly nucleophilic anionic, or even dianionic, intermediates that could be advantageously used for C-C bond formation (for instance, for the stereocontrolled construction of quaternary stereocenters ${ }^{[8]}$ ). One could even envision the coupling of a reductive dearomatization process and an annulation reaction to open short routes for the preparation of complex cyclic frameworks present in natural and bioactive compounds. Notwithstanding these attractive possibilities, there have only appeared a handful of publications describing useful results in this area. $^{[9]}$

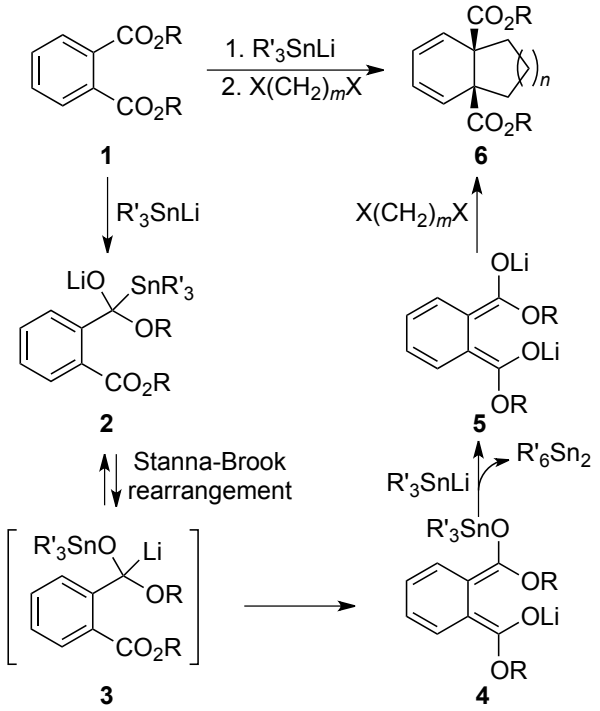

Scheme 1. Mechanism for the Dearomatization-Alkylation Procedure Mediated by $\mathrm{Me}_{3} \mathrm{SnLi}$.

In the past few years we have undertaken a program to broaden the synthetic utility of dearomatization reactions by coupling them to annulation protocols. In this area, we have reported the successful pairing of a novel dearomatization reaction of phthalates and related diesters, brought about by anionic tin nucleophiles, with a bis-alkylation reaction. This tandem sequence allows the stereoselective preparation of 6,5-, 6,6- and 6,7-fused carbobicyclic and heterobicyclic systems, with the concomitant formation of one or two quaternary stereocenters in the process. ${ }^{[10]}$ Our procedure involves the treatment of benzene and pyridine diesters with $\mathrm{R}_{3} \mathrm{SnLi}$, to provide highly nucleophilic bis-enolates (a process in which a stanna-Brook rearrangement ${ }^{[11]}$ is involved) followed by trapping the intermediates with 1, $\omega$-dihaloalkanes and related biselectrophiles. This dearomatization-alkylation procedure (Scheme 1) does not result from the nucleophilic addition of trialkylstannyllithium to the electron-deficient aromatic ring (as in 
many nucleophilic addition-initiated dearomatization reactions),${ }^{[1 \mathrm{a}, 3]}$ but instead from 1,2-addition to a carboxylate group, followed by 1,2 Li-Sn rearrangement of the initial stannyl alkoxide adduct (Scheme 1). Reaction of $\mathbf{4}$ with a second equivalent of $\mathrm{R}_{3} \mathrm{SnLi}$ gives rise to the bis-enolate $\mathbf{5}$, which is finally trapped with different bis-electrophiles to yield the observed bicyclic products.

Herein we report the results of our work aimed at increasing the usefulness and applicability of this methodology. Firstly we explored the scope of the reaction with regards to the type of aromatic diesters that could be used (for example, five-membered ring heteroaromatics, such as furan, thiophene, benzofuran, as well as naphthalene-derivatives). Secondly we undertook the task of finding reaction conditions that would require only substoichiometric (catalytic) amounts of tin reagents (due to their toxicity and expensive nature). Finally we engaged in the development of an enantioselective variant of this transformation.

\section{Results and Discussion}

We first studied the behaviour of 5-membered-ring aromatic heterocycles, such as furan and thiophene. Dearomatized furans ${ }^{[12]}$ have been previously obtained by decarboxylative Claisen rearrangement, ${ }^{[\mathrm{b}]}[2,3]$-Still-Wittig rearrangement, ${ }^{[13]}$ aryl radical addition $^{[14]}$ or nucleophilic addition to carbene complexes of chromium, ${ }^{[15]}$ among other methods. ${ }^{[16]}$

Furan diester $7(\mathrm{X}=\mathrm{O})$ was prepared by Fischer esterification in $i \mathrm{PrOH}$ of the corresponding diacid, which in turn was obtained by regioselective deprotonation at $\mathrm{C}-2$ of 3 -furoic acid with $\mathrm{BuLi}$ followed by quenching with carbon dioxide. ${ }^{[17]}$ Treatment of a THF solution of 7 with $\mathrm{Me}_{3} \mathrm{SnLi}(215 \mathrm{~mol}-\%)$ at low temperature, followed by trapping of the intermediate bis-enolate with 1,3diiodopropane (120 mol-\%) afforded the 5,5-fused bicyclic compound 9a. The ${ }^{1} \mathrm{H}$ NMR of the crude reaction mixture showed dearomatized 9a as the main product, together with minor proportions of starting material, a ring-opened product, and the monoacid derived from partial hydrolysis of $7 .^{[18]}$ After chromatographic purification, 9a was isolated in $63 \%$ yield. When 1,4-diiodobutane was used as the electrophile under the same reaction conditions, 9b was obtained in 59\% yield. The ringforming bis-alkylation of the furan-derived bis-enolate proved to be more difficult with 1,5-diiodopentane but, as observed previously with phthalate and pyridine diesters, ${ }^{[10]}$ the 5,7 -fused bicycle $9 \mathrm{c}$ could also be prepared, albeit in a lower yield (48\%), by warming up the reaction mixture to $40{ }^{\circ} \mathrm{C}$. All bicyclic compounds were obtained with complete stereoselectivity, as only one stereoisomer was detected in the ${ }^{1} \mathrm{H}$ NMR spectra of the crude reaction mixtures.

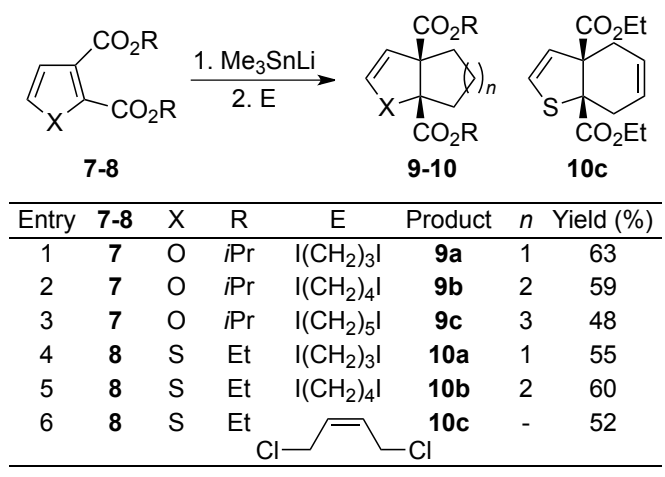

Scheme 2. Dearomatizing Anionic Cyclization of Furan and Thiophene Diesters.

Diethyl thiophene-2,3-dicarboxylate $(8, X=S)$ was obtained by Fischer esterification of the corresponding diacid, which in turn was prepared by dilithiation of thiophene 2-carboxylic acid with BuLi followed by quenching with carbon dioxide. ${ }^{[19]}$ In a manner analogous to that of furan 7, when the dearomatization-bisalkylation procedure was applied to 8, fused 5,5-, and 5,6-ring systems were obtained after sequential treatment with $\mathrm{Me}_{3} \mathrm{SnLi}$ and 1,3-diiodopropane (10a, 55\%) or 1,4-diiodobutane (10b, 60\%). Again some starting material and a ring-opened product were observed in the reaction mixture. When a functionalized biselectrophile, such as cis-1,4-dichloro-2-butene, was used the expected tetrahydrobenzothiophene $10 \mathrm{c}$ was isolated in $52 \%$ yield.

We then investigated the behaviour of benzofuran diester 11. Benzofurans have been used recently in dearomatizing [4+2] cycloadditions, ${ }^{[7]}$ and radical reactions. ${ }^{[20]}$ Under stanna-Brook conditions, benzofuran 11 was transformed into the corresponding bis-enolate that was alkylated with different $1, \omega$-dihaloalkanes to give the corresponding tricyclic compound $12(\mathrm{n}=1-3)$ in good yields (see Scheme 3).

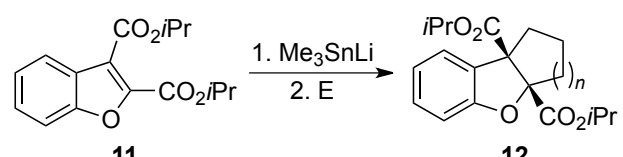

11

12

\begin{tabular}{ccccc}
\hline Entry & $\mathrm{E}$ & Product & $n$ & Yield (\%) \\
\hline 1 & $\mathrm{I}\left(\mathrm{CH}_{2}\right)_{3} \mathrm{I}$ & $\mathbf{1 2 a}$ & 1 & 70 \\
2 & $\mathrm{I}\left(\mathrm{CH}_{2}\right)_{4} \mathrm{I}$ & $\mathbf{1 2 b}$ & 2 & 68 \\
3 & $\mathrm{I}\left(\mathrm{CH}_{2}\right)_{5} \mathrm{I}$ & $\mathbf{1 2 c}$ & 3 & 59 \\
4 & & & & \\
\hline
\end{tabular}

Scheme 3. Dearomatizing Anionic Cyclizations of Benzofuran Diesters.

Naphthalene-diester derivatives, with different patterns of substitution, were also investigated as substrates for our dearomatization-annulation methodology. We first explored the behaviour of naphthalene systems possessing the two required carboxylate moieties in the same ring. Unfortunately, under the reaction conditions employed, 1,2- and 2,3-disubstituted naphthalenes afforded complex reaction mixtures. The results obtained with 1,2-disubstituted naphthalene may be due to the instability of the intermediate bis-enolate to form, due to the steric crowding around the substituent in position 1. The total loss of the aromaticity of both rings in the intermediate bis-enolate derived from the 2,3-disubstituted naphthalene diester can account for the observed results in this particular case. In stark contrast with these negative results, reaction of diisopropyl naphthalene-1,4dicarboxylate (13) with $\mathrm{Me}_{3} \mathrm{SnLi}$ followed by addition of 1,3dibromopropane provided tricyclic compound 15a in an $87 \%$ isolated yield. The analogous reaction using 1,4-diiodobutane as the bis-electrophile did not provide the desired tricyclic diester, but instead a mixture of mono- and dialkylated compounds. The use of a more rigid bis-electropile, such as 1,2-bis(chloromethyl)benzene, proved more successful and allowed the preparation of the 
tetracyclic product $\mathbf{1 5 b}$ in $60 \%$ yield. However, with 1,4-dichloro2-butene no alkylation was observed and starting ester $\mathbf{1 3}$ was recovered. This unexpected result is probably due to the fact that the electrophile acts as a chlorinating agent with concomitant liberation of butadiene, and not as a C-electrophile.
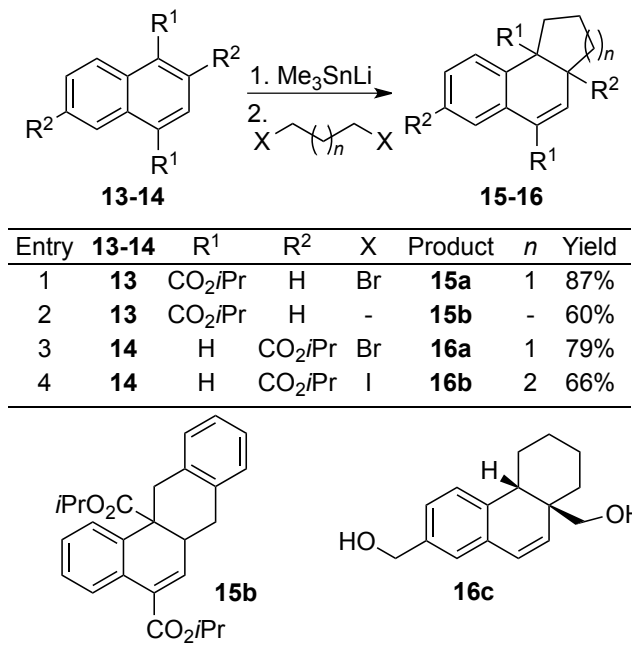<smiles>OCc1ccc2c(c1)C=CC1(CO)CCCC[C@H]21</smiles>

$16 \mathrm{c}$

Scheme 4. Dearomatizing Anionic Cyclizations of Naphthalene Derivatives.

We then proceeded to study the behaviour of naphthalene systems where the required carboxylates were attached to different rings. Complex mixtures were obtained for the reaction of 1,5naphthalene dicarboxylate with $\mathrm{Me}_{3} \mathrm{SnLi}$ and 1, $\omega$-dihaloalkanes, but when diisopropyl naphthalene-2,6-dicarboxylate (14) was treated with $\mathrm{Me}_{3} \mathrm{SnLi}$ followed by the addition of 1,3dibromopropane or 1,4-diiodobutane, the desired cyclized products 16a and 16b were isolated in 79 and $66 \%$ yield, respectively. The syn-fusion of the new ring was confirmed by X-ray crystallographic analysis of the diol 16c, obtained by $\mathrm{LiAlH}_{4}$ reduction of $16 \mathbf{b}$ in THF at $0{ }^{\circ} \mathrm{C}{ }^{[21]}$

We next decided to explore whether the presence of two carboxylate groups in the aromatic system was an absolute requirement for the dearomatization reaction to take place. In principle, the stanna-Brook reaction could also take place if one of the carboxylate groups were replaced by a different electronwithdrawing group. To explore this hypothesis we studied the behaviour of several benzoates further substituted in their $p$ - and $o$ positions with different electron-withdrawing groups. Complex reaction mixtures were obtained when keto, formyl, nitro or cyano benzoates $^{[22]}$ were used as substrates, but $p$-imino substituted benzoates, bearing a PMP moiety as the $N$-protecting group, were found to provide clean reactions when submitted to the stannaBrook-bis-alkylation protocol. Interestingly, we did not detect dearomatized products after treatment of $p$-imino-benzoate 17 with $\mathrm{Me}_{3} \mathrm{SnLi}$ followed by the addition of an electrophile, instead we observed that the bis-alkylation took place on the $\mathrm{N}$ and $\mathrm{C}$ atoms originally forming the imine group, and that the regioselectivity of the process could be easily controlled. Thus, treatment of $\mathbf{1 7}$ with $\mathrm{Me}_{3} \mathrm{SnLi}$ in THF at low temperature followed by addition of 1iodopropane, afforded the C-alkylated, secondary benzylamine 18a in $78 \%$ yield. The alkylation reaction was shown to be regioselective as it proceeded exclusively on the imine carbon. However, the use of a harder electrophile, such as $\mathrm{Me}_{2} \mathrm{SO}_{4}$, gave mainly the $N$-methylated, C-unsubstituted product $\mathbf{1 8 b}$. Additionally, the use of bis-electrophiles such as 1,3dibromopropane or 1,4-diiodobutane led to the corresponding pyrrolidine 18c or piperidine $18 \mathrm{~d}$ in good yields. $\delta$-Lactam $18 \mathrm{e}$ was also easily prepared in good yield when methyl $\gamma$-iodobutyrate was used as the bis-electrophile.

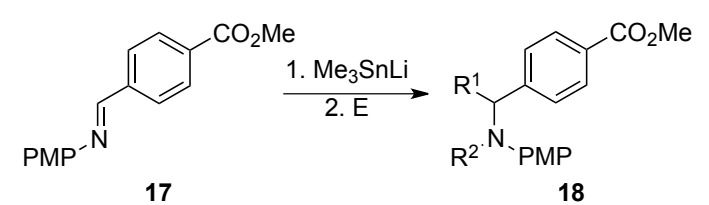

\begin{tabular}{cccccc}
\hline Entry & Product & $\mathrm{E}$ & $\mathrm{R}^{1}$ & $\mathrm{R}^{2}$ & Yield (\%) \\
\hline 1 & $\mathbf{1 8 a}$ & $\mathrm{I}\left(\mathrm{CH}_{2}\right)_{2} \mathrm{CH}_{3}$ & $\mathrm{Pr}$ & $\mathrm{H}$ & 78 \\
2 & $\mathbf{1 8 b}$ & $\mathrm{Me}_{2} \mathrm{SO}_{4}$ & $\mathrm{H}$ & $\mathrm{Me}$ & 60 \\
3 & $\mathbf{1 8 c}$ & $\mathrm{Br}\left(\mathrm{CH}_{2}\right)_{3} \mathrm{Br}$ & $\left(\mathrm{CH}_{2}\right)_{3}$ & 87 \\
4 & $\mathbf{1 8 d}$ & $\mathrm{I}\left(\mathrm{CH}_{2}\right)_{4} \mathrm{I}$ & $\left(\mathrm{CH}_{2}\right)_{4}$ & 75 \\
5 & 18e & $\mathrm{I}\left(\mathrm{CH}_{2}\right)_{3} \mathrm{CO}_{2} \mathrm{Me}$ & $\left(\mathrm{CH}_{2}\right)_{3} \mathrm{CO}$ & 67 \\
\hline
\end{tabular}

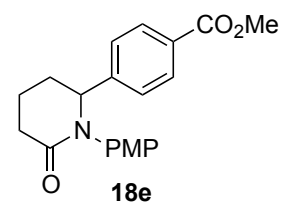<smiles>COc1ccc(C=PN=P)cc1</smiles>

Scheme 5. $\mathrm{Me}_{3} \mathrm{SnLi}$ Addition to $p$-Imino Benzoate 17.

In all the annulations described so far, the required $\mathrm{Me}_{3} \mathrm{SnLi}$ was prepared by treatment of a THF solution of hexamethyldistannane with $\mathrm{MeLi}^{[23]}$ because of the simplicity of the procedure and the homogeneity of the reaction mixture obtained, although in this process one equivalent of tin is wasted as $\mathrm{Me}_{4} \mathrm{Sn}$. An alternative procedure for the preparation of $\mathrm{Me}_{3} \mathrm{SnLi}$ involves the reaction of $\mathrm{Me}_{6} \mathrm{Sn}_{2}$ or $\mathrm{Me}_{3} \mathrm{SnCl}$ with excess lithium in THF. ${ }^{[24]}$ Since, according to our proposed mechanism for the stanna-Brook rearrangement, a molecule of $\mathrm{Me}_{6} \mathrm{Sn}_{2}$ is obtained per bis-enolate molecule formed, we decide to explore if this di-tin compound could be recycled into $\mathrm{Me}_{3} \mathrm{SnLi}$ in situ, thus turning the procedure catalytic in the tin reagent. To test this hypothesis, we prepared a solution of substoichiometric amount of $\mathrm{Me}_{3} \mathrm{SnLi}$ from $\mathrm{Me}_{3} \mathrm{SnCl}$ (10 mol-\%) and excess lithium in THF at room temperature for 30 min. After cooling to $-78{ }^{\circ} \mathrm{C}$, a solution of diisopropyl phthalate $(100 \mathrm{~mol}-\%)$ in THF was added and the resulting mixture was stirred while a dark red color developed. Addition of 1,3dibromopropane to this dark red solution provided the hydrindane 21a, thus proving that $\mathrm{Me}_{6} \mathrm{Sn}_{2}$ could be successfully recycled into $\mathrm{Me}_{3} \mathrm{SnLi}$ under the reaction conditions used. After some experimentation we discovered that the bis-enolate can be prepared after $16 \mathrm{~h}$ at $-78^{\circ} \mathrm{C}$ by using 2000 mol- $\%$ of lithium and 10 mol-\% of $\mathrm{Me}_{3} \mathrm{SnCl}$. Under these conditions we have prepared the hydrindanes $21 \mathrm{a}$ and $22 \mathrm{a}$ in $77 \%$ and $60 \%$ yield, respectively (see Scheme 6). The hexahydronaphthalene 21b was isolated in $68 \%$ yield when 1,4-diiodobutane was used as electrophile. This substoichiometric procedure can also be successfully applied to heteroaromatic diesters, as thiophene $8(X=S)$ provided the expected bicycle $10 \mathrm{~b}$ in $56 \%$ yield. Despite the fact that the yields obtained using this catalytic procedure are slightly lower than when stoichiometric $\mathrm{Me}_{3} \mathrm{SnLi}$ is used, ${ }^{[10]}$ we consider that the economic savings and the lower toxicity of the process make it a valuable alternative. Some limitations to the general applicability of this catalytic procedure were found nevertheless, since no reaction was observed when terephthalate and naphthalene diesters were subjected to these conditions. 


\begin{tabular}{|c|c|c|c|c|c|c|}
\hline & $\mathrm{CO}_{2} i$ & $\begin{array}{l}1 . \\
M\end{array}$ & & $\begin{array}{l}\widehat{n}_{\mathrm{X}}^{0 \%)} \\
\stackrel{(10 \%)}{\longrightarrow}\end{array}$ & & $\begin{array}{l}\mathrm{CO}_{2} i \mathrm{Pr} \\
21-22\end{array}$ \\
\hline Entry & Diester & $\mathrm{R}^{1}$ & $x$ & Product & $n$ & Yield (\%) \\
\hline 1 & 19 & $\mathrm{H}$ & $\mathrm{Br}$ & $21 a$ & 1 & 77 \\
\hline 2 & 19 & $\mathrm{H}$ & I & $21 b$ & 2 & 68 \\
\hline 3 & 20 & $\mathrm{Me}$ & I & $22 a$ & 1 & 60 \\
\hline 4 & 8 & - & I & $10 \mathrm{~b}$ & - & 56 \\
\hline
\end{tabular}

Scheme 6. Results Using Substoichiometric Sn-reagent.

The next step in our exploration of this chemistry was the development of an asymmetric version of this methodology. Our entry to the asymmetric construction of quaternary centers relies on the use of esters derived from chiral alcohol auxiliaries. Thus we explored the behaviour of chiral bis-enolates in which all stereochemical information resides in the alcoholic component of the ester functionality. In particular, we chose for these preliminary assays the hindered esters derived from picolinic acid $\mathbf{2 3}$ and the following alcohols: (-)-menthol, (-)-borneol, (1R,2S)-trans-2phenyl-1-cyclohexanol, $(S)$-1-phenylethanol and (-)-8phenylmenthol. All esters were prepared using EDC as the coupling agent and DMAP as the nucleophilic catalyst in $\mathrm{CH}_{2} \mathrm{Cl}_{2}$. Sequential treatment of esters 24 with $\mathrm{Me}_{3} \mathrm{SnLi}$, to generate the chiral bis-enolate, followed by addition of 1,3-dibromopropane for the alkylation-cyclization process, afforded tetrahydroindolizines 25 in good unoptimized yields. As shown in Scheme 7, the best diastereomeric ratio (99:1) was obtained using (-)-8-phenylmenthol as chiral auxiliary (25e). A favorable face-to-face $\pi-\pi$ interaction can explain the high degree of stereocontrol obtained in the alkylation of the bis-enolate (with the pending 8-phenylmenthyl moiety ${ }^{[25]}$ with 1,3-dibromopropane. Furthermore, when 1,4dibromobutane and 1,5-diiodopentane were used as electrophiles, the corresponding quinolizine 26e and azepine 27e were also obtained with good diastereoselectivities (94:6 and 93:7, respectively). Single crystals of 25e suitable for X-ray analysis were obtained by recrystallization from $\mathrm{Et}_{2} \mathrm{O} / \mathrm{CH}_{2} \mathrm{Cl}_{2}$. The X-ray analysis revealed that the absolute configuration of indolizine $\mathbf{2 5} \mathbf{e}$ was $R .^{[21]}$

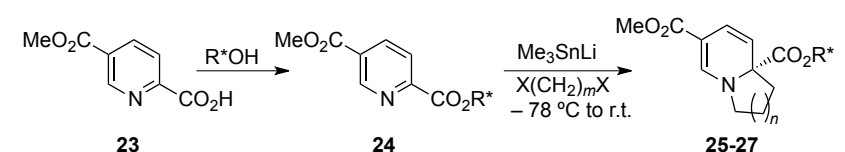

\begin{tabular}{|c|c|c|c|c|c|c|c|}
\hline $\mathrm{R}^{*} \mathrm{OH}$ & 24 & Yield & Electrophile & Product & $n$ & Yield & $d r$ \\
\hline (-)-menthol, a & $24 a$ & $60 \%$ & $\mathrm{Br}\left(\mathrm{CH}_{2}\right)_{3} \mathrm{Br}$ & $25 a$ & 1 & $58 \%$ & $50: 50$ \\
\hline (-)-borneol, b & 24b & $66 \%$ & $\mathrm{Br}\left(\mathrm{CH}_{2}\right)_{3} \mathrm{Br}$ & $25 b$ & 1 & $73 \%$ & $60: 40$ \\
\hline$(1 R, 2 S)$-2-phenylcyclohexanol, c & 24c & $87 \%$ & $\mathrm{Br}\left(\mathrm{CH}_{2}\right)_{3} \mathrm{Br}$ & $25 c$ & 1 & $88 \%$ & $67: 33$ \\
\hline (S)-1-phenylethanol, d & 24d & $70 \%$ & $\mathrm{Br}\left(\mathrm{CH}_{2}\right)_{3} \mathrm{Br}$ & 25d & 1 & $71 \%$ & $87: 23$ \\
\hline (-)-8-phenylmenthol, e & $24 \mathrm{e}$ & $81 \%$ & $\mathrm{Br}\left(\mathrm{CH}_{2}\right)_{3} \mathrm{Br}$ & $25 \mathrm{e}$ & 1 & $79 \%$ & $99: 1$ \\
\hline (-)-8-phenylmenthol, e & $24 \mathrm{e}$ & & $\mathrm{Br}\left(\mathrm{CH}_{2}\right)_{4} \mathrm{Br}$ & $26 e$ & 2 & $58 \%$ & $94: 6$ \\
\hline (-)-8-phenylmenthol, $\mathbf{e}$ & $24 \mathrm{e}$ & & $\mathrm{I}\left(\mathrm{CH}_{2}\right)_{5} \mathrm{I}$ & $27 e$ & 3 & $62 \%$ & $93: 7$ \\
\hline $\mathrm{R}^{*} \mathrm{OH}:$ & N & & c & d & & 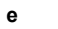 & \\
\hline
\end{tabular}

Scheme 7. Asymmetric Dearomatization-Cyclization of Pyridine Diesters.
$\mathrm{Me}_{3} \mathrm{SnLi}$, followed by the addition of primary halides (Scheme 8), the expected products were obtained with excellent enantioselectivity and fair to excellent chemical yields.

A limitation of this enantioselective dearomatizing annulation was found when our attempts to carry out the reactions using substoichiometric amounts of tin compounds failed. Complex reaction mixtures were obtained from these experiments. We believe that the slow formation of the required bis-enolates under the substoichiometric conditions allows ample opportunity for decomposition reactions to take place, probably caused by the bulkiness of the chiral auxiliary.

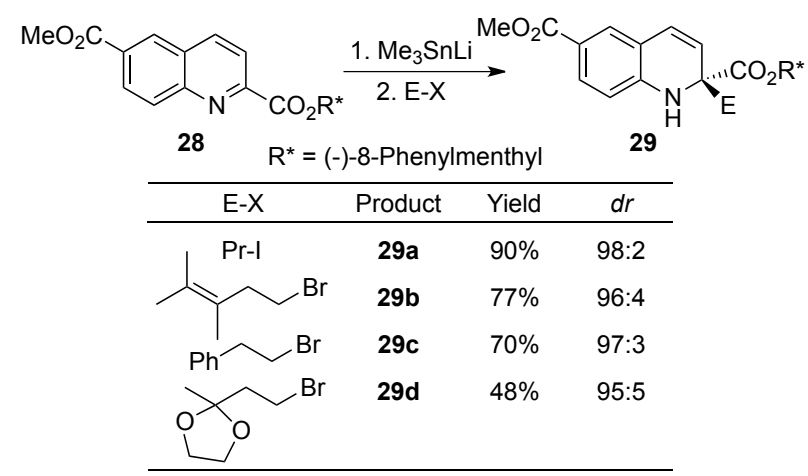

Scheme 8. Asymmetric Dearomatization-Alkylation of Quinoline Diester.

As a synthetic application of this methodology, we developed an enantioselective approach to the tricyclic benzofuran derivative $\mathbf{3 3}$, a projected intermediate for the synthesis of analogs of galantamine,${ }^{[26]}$ an alkaloid that acts as a selective, reversible, and competitive acetylcholinesterase inhibitor. 7-Methoxybenzofuran 30 was prepared from commercially available 2-methoxyphenol in three steps ${ }^{[27]}$ in $41 \%$ overall yield. Selective hydrolysis of the ester in the 2-position was quantitatively achieved by using $\mathrm{LiOH}$ in a 1:1 dioxane: $\mathrm{H}_{2} \mathrm{O}$ mixture. Esterification of 31 with (-)-8phenylmenthol in the presence of EDC and DMAP in $\mathrm{CH}_{2} \mathrm{Cl}_{2}$, afforded chiral diester 32 in $84 \%$ yield. Treatment of $\mathbf{3 2}$ with $\mathrm{Me}_{3} \mathrm{SnLi}$ to give a chiral bis-enolate, followed by alkylation with cis-2-butene-1,4-diol dimesylate led to the tricycle $\mathbf{3 3}$ in 50\% yield. Careful examination of the ${ }^{1} \mathrm{H}$ NMR of the crude reaction mixture showed that the reaction took place with very high diastereoselectivity as only one diasteroisomer could be identified. To confirm the level of diastereoselection, the tricyclic compound was reduced to the diol $\mathbf{3 4}$ with $\mathrm{LiAlH}_{4}$ in $75 \%$ yield and then the derived esters from $\mathbf{3 4}$ and both enantiomers of $\alpha$ methoxyphenylacetic (MPA) acid ${ }^{[28]}$ were prepared. $500 \mathrm{MHz}{ }^{1} \mathrm{H}$ NMR spectroscopy analyses of the crude mixtures showed an enantiomeric ratio of 98:2, proving again that (-)-8-phenylmenthol is an excellent chiral inductor for the bis-alkylation of lithium bisenolates obtained from the stanna-Brook rearrangement of heteroaromatic diesters.

Once we had shown the successful enantioselective dearomatization-annulation process in pyridine diesters, we chose a different heteroaromatic system to prove the enantioselective dearomatization-alkylation with more elaborated nucleophiles and electrophiles. Thus when quinoline diester $\mathbf{2 8}$ was treated with 


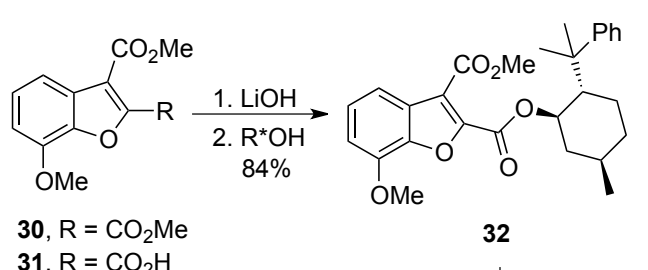

31, $\mathrm{R}=\mathrm{CO}_{2} \mathrm{H}$

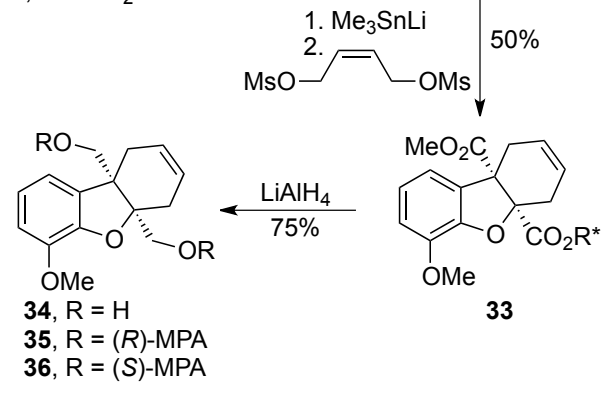

Scheme 9. Asymmetric Dearomatization-Cyclization of Benzofuran 30.

\section{Conclusions}

In summary, we have developed a one-pot, enantioselective strategy for the dearomatization-annulation of aromatic diesters to give a range of highly functionalized polycyclic molecules with excellent enantioselectivities. For some compounds we have found experimental conditions for performing the reaction with substoichiometric amounts of the required tin reagent. Currently, we are investigating the application of this process to the synthesis of natural products.

\section{Experimental Section}

Diisopropyl furan-2,3-dicarboxylate (7). A solution of furan-2,3dicarboxylic acid ${ }^{[17]}(625 \mathrm{mg}, 4.0 \mathrm{mmol})$ in toluene $(40 \mathrm{~mL})$ and $i \mathrm{PrOH}(20$ $\mathrm{mL})$ was treated with $\mathrm{H}_{2} \mathrm{SO}_{4}(130 \mu \mathrm{L})$ and refluxed using a Dean-Stark trap. During the first $6 \mathrm{~h}, 6 \mathrm{~mL}$ of distillate were withdrawn every hour and replenished by an equal volume of $2: 1$ toluene- $i \mathrm{PrOH}$ mixture. After $24 \mathrm{~h}$, the solution was cooled to room temperature and concentrated in vacuo to 5 $\mathrm{mL}$, diluted with $\mathrm{CH}_{2} \mathrm{Cl}_{2}$, and washed with cold, saturated $\mathrm{NaHCO}_{3}$. The organic extract was washed with water and brine, dried and concentrated to an oily residue which was purified by bulb-to-bulb distillation under reduced pressure, and then stored as a colorless oil over $4 \AA$ molecular sieves (675 mg, 70\%): ${ }^{1} \mathrm{H}$ NMR $\left(250 \mathrm{MHz}, \mathrm{CDCl}_{3}\right): \delta=7.46(\mathrm{~d}, J=1.8 \mathrm{~Hz}$, $1 \mathrm{H}), 6.70(\mathrm{~d}, J=1.8 \mathrm{~Hz}, 1 \mathrm{H}), 5.25$ (hept, $J=6.3 \mathrm{~Hz}, 1 \mathrm{H}), 5.20$ (hept, $J=$ $6.3 \mathrm{~Hz}, 1 \mathrm{H}), 1.35(\mathrm{~d}, J=6.3 \mathrm{~Hz}, 6 \mathrm{H}), 1.34(\mathrm{~d}, J=6.3 \mathrm{~Hz}, 6 \mathrm{H}) ;{ }^{13} \mathrm{C} \mathrm{NMR}$ $\left(62.9 \mathrm{MHz}, \mathrm{CDCl}_{3}\right): \delta=161.8,157.2,144.1,143.8,124.1,112.6,69.3,69.0$, 21.57, 21.55; IR (KBr): $v=1728 \mathrm{~cm}^{-1}$; HRMS (ESI): $m / z$ calcd for $\mathrm{C}_{12} \mathrm{H}_{17} \mathrm{O}_{5}: 241.1071\left[M+\mathrm{H}^{+}\right]$; found: 241.1079 ; elemental analysis calcd (\%) for $\mathrm{C}_{12} \mathrm{H}_{16} \mathrm{O}_{5}$ : C 59.99, H 6.71; found: C 59.89, H 6.83.

Preparation of $\mathrm{Me}_{3} \mathrm{SnLi}$. MeLi (215 mol-\%, 1.6 $\left.\mathrm{M}_{\text {in }} \mathrm{Et}_{2} \mathrm{O}\right)$ was added to a $0{ }^{\circ} \mathrm{C}$ solution of $\mathrm{Me}_{6} \mathrm{Sn}_{2}(220 \mathrm{~mol}-\%)$ in THF $(0.5 \mathrm{M})$. After $15 \mathrm{~min}$, the solution was cooled to $-78{ }^{\circ} \mathrm{C}$ and treated with a solution of the corresponding aromatic diester (100 mol-\%) in THF (0.2 M).

\section{Diisopropyl 4,5,6,6a-tetrahydro-3a $H$-cyclopenta[b]furan-3a,6a-}

dicarboxylate (9a). A $-78{ }^{\circ} \mathrm{C}$ solution of $\mathrm{Me}_{3} \mathrm{SnLi}$ in $\mathrm{THF}$ was treated with a solution of $7(120 \mathrm{mg}, 0.50 \mathrm{mmol})$ in THF and stirred for $20 \mathrm{~min}$, warmed to $-50^{\circ} \mathrm{C}$ and stirred for $40 \mathrm{~min}$. 1,3-Diiodopropane ( $\left.70 \mu \mathrm{L}, 0.61 \mathrm{mmol}\right)$ was added, and the mixture stirred for $3 \mathrm{~h}$ at $-50{ }^{\circ} \mathrm{C}$ and then for $18 \mathrm{~h}$ while slowly warming to room temperature. The reaction was quenched by adding $\mathrm{pH} 5.6$ acetate buffer $(5 \mathrm{~mL})$ and then partitioned between $\mathrm{CH}_{2} \mathrm{Cl}_{2}$ $(10 \mathrm{~mL})$ and acetate buffer $(5 \mathrm{~mL})$. The aqueous layer was extracted with $\mathrm{CH}_{2} \mathrm{Cl}_{2}$ and the combined organic extracts were washed with brine, dried over $\mathrm{Na}_{2} \mathrm{SO}_{4}$ and concentrated. The crude product showed to be an inseparable mixture of starting furan and desired product so it was dissolved in a 1:1 dioxane-water mixture $(4 \mathrm{~mL})$ and treated with $\mathrm{LiOH} \cdot \mathrm{H}_{2} \mathrm{O}(63 \mathrm{mg}, 1.5 \mathrm{mmol})$. After stirring for $3 \mathrm{~h}$ at room temperature, pH 5.6 acetate buffer $(15 \mathrm{~mL})$ was added. The aqueous layer was extracted with $\mathrm{CH}_{2} \mathrm{Cl}_{2}$ and the combined organic phase was washed with brine, dried $\left(\mathrm{Na}_{2} \mathrm{SO}_{4}\right)$, filtered and concentrated. The residue was purified by column chromatography (neutral $\mathrm{Al}_{2} \mathrm{O}_{3}, \mathrm{CH}_{2} \mathrm{Cl}_{2} /$ hexane $1: 1$ ) to give $89 \mathrm{mg}(63 \%)$ of 9a as a colorless oil: ${ }^{1} \mathrm{H}$ NMR $\left(250 \mathrm{MHz}, \mathrm{CDCl}_{3}\right): \delta=6.43(\mathrm{~d}, J=2.7$ $\mathrm{Hz}, 1 \mathrm{H}), 4.98$ (hept, $J=6.3 \mathrm{~Hz}, 1 \mathrm{H}), 4.90$ (hept, $J=6.3 \mathrm{~Hz}, 1 \mathrm{H}), 4.76$ (d, $J$ $=2.7 \mathrm{~Hz}, 1 \mathrm{H}), 2.29-2.03(\mathrm{~m}, 3 \mathrm{H}), 1.89-1.61(\mathrm{~m}, 3 \mathrm{H}), 1.18(\mathrm{~m}, 12 \mathrm{H}) ;{ }^{13} \mathrm{C}$ NMR (62.9 MHz, $\left.\mathrm{CDCl}_{3}\right): \delta=172.3,170.3,147.0,103.9,97.3,68.9,68.5$, 68.2 , 39.9, 37.4, 23.5, 21.58, 21.56, 21.50, 21.46; IR (KBr): $v=1729 \mathrm{~cm}^{-1}$; elemental analysis calcd (\%) for $\mathrm{C}_{15} \mathrm{H}_{22} \mathrm{O}_{5}: \mathrm{C} 63.81, \mathrm{H} 7.85$; found: $\mathrm{C}$ 63.41, H 8.25

Diisopropyl 3a,4,5,6,7,7a-hexahydrobenzofuran-3a,7a-dicarboxylate (9b). Following the procedure described above for 9a, except using 1,4diiodobutane $(80 \mu \mathrm{L}, 0.61 \mathrm{mmol})$, provided $9 \mathbf{b}$ as a colorless oil $(87 \mathrm{mg}$, 59\%): ${ }^{1} \mathrm{H}$ NMR (250 MHz, $\left.\mathrm{CDCl}_{3}\right): \delta=6.35(\mathrm{~d}, J=2.7 \mathrm{~Hz}, 1 \mathrm{H}), 5.07$ (hept, $J=6.3 \mathrm{~Hz}, 1 \mathrm{H}), 4.92(\mathrm{~m}, 2 \mathrm{H}), 2.03(\mathrm{~m}, 2 \mathrm{H}), 1.88(\mathrm{~m}, 2 \mathrm{H}), 1.46(\mathrm{~m}$, $4 \mathrm{H}), 1.28(\mathrm{~d}, J=6.3 \mathrm{~Hz}, 3 \mathrm{H}), 1.23(\mathrm{~d}, J=6.3 \mathrm{~Hz}, 3 \mathrm{H}), 1.17(\mathrm{~d}, J=6.3 \mathrm{~Hz}$, $6 \mathrm{H}) ;{ }^{13} \mathrm{C} \mathrm{NMR}\left(62.9 \mathrm{MHz}, \mathrm{CDCl}_{3}\right): \delta=172.8,170.8,146.0,106.4,87.9$, 68.4, 68.0, 57.2, 32.4, 29.1, 21.6, 21.41, 21.36, 21.3, 20.1, 19.2; IR (KBr): $v=1729 \mathrm{~cm}^{-1}$; HRMS (ESI): $m / z$ calcd for $\mathrm{C}_{16} \mathrm{H}_{25} \mathrm{O}_{5}: 297.1697\left[M+\mathrm{H}^{+}\right]$; found: 297.1697; elemental analysis calcd (\%) for $\mathrm{C}_{16} \mathrm{H}_{24} \mathrm{O}_{5}: \mathrm{C} 64.84, \mathrm{H}$ 8.16; found: C 64.51, H 8.18.

Diisopropyl 4,5,6,7,8,8a-hexahydro-3a $H$-cyclohepta[b]furan-3a,8adicarboxylate $(9 \mathrm{c}) . \mathrm{A}-78{ }^{\circ} \mathrm{C}$ solution of $\mathrm{Me}_{3} \mathrm{SnLi}$ in THF was treated with a solution of 7 (120 mg, $0.50 \mathrm{mmol})$ in THF and stirred for $1 \mathrm{~h} .1,5-$ Diiodopentane ( $90 \mu \mathrm{L}, 0.60 \mathrm{mmol})$ in DMF $(2 \mathrm{~mL})$ was added, and the reaction mixture was stirred for $14 \mathrm{~h}$ while warming from $-78^{\circ} \mathrm{C}$ to room temperature, and then at $40{ }^{\circ} \mathrm{C}$ for $6 \mathrm{~h}$. Work-up as for $9 \mathbf{a}$ afforded $9 \mathbf{c}(74$ $\mathrm{mg}, 48 \%)$ as a colorless oil after bulb-to-bulb distillation $(0.01 \mathrm{mmHg}, 80$ $\left.{ }^{\circ} \mathrm{C}\right):{ }^{1} \mathrm{H}$ NMR $\left(250 \mathrm{MHz}, \mathrm{CDCl}_{3}\right): \delta=6.41(\mathrm{~d}, J=2.7 \mathrm{~Hz}, 1 \mathrm{H}), 4.92(\mathrm{~m}$, $2 \mathrm{H}), 4.83(\mathrm{~d}, J=2.7 \mathrm{~Hz}, 1 \mathrm{H}), 2.18(\mathrm{~m}, 1 \mathrm{H}), 1.94(\mathrm{~m}, 3 \mathrm{H}), 1.73-1.24(\mathrm{~m}$, $6 \mathrm{H}), 1.18(\mathrm{~m}, 12 \mathrm{H}) ;{ }^{13} \mathrm{C} \mathrm{NMR}\left(62.9 \mathrm{MHz}, \mathrm{CDCl}_{3}\right): \delta=173.7,171.4,144.6$, 105.5, 92.7, 68.6, 68.4, 64.0, 35.3, 34.1, 30.7, 24.6, 22.8, 21.42, 21.38; IR $(\mathrm{KBr}): v=1737 \mathrm{~cm}^{-1}$; elemental analysis calcd $(\%)$ for $\mathrm{C}_{17} \mathrm{H}_{26} \mathrm{O}_{5}: \mathrm{C} 65.78$, H 8.44; found: C 65.95, H 8.27.

Diethyl 4,5,6,6a-tetrahydro-3aH-cyclopenta[b]thiophene-3a,6adicarboxylate (10a). $\mathrm{A}-78^{\circ} \mathrm{C}$ solution of $\mathrm{Me}_{3} \mathrm{SnLi}$ in $\mathrm{THF}$ was treated with a solution of $\mathbf{8}^{[19]}(105 \mathrm{mg}, 0.46 \mathrm{mmol})$ in THF and stirred for $1 \mathrm{~h}$. 1,3Diiodopropane $(60 \mu \mathrm{L}, 0.52 \mathrm{mmol})$ was added, and the mixture stirred for 1 $\mathrm{h}$ at $-78^{\circ} \mathrm{C}$ and then for $14 \mathrm{~h}$ while slowly warming to room temperature. Work-up as for 9a afforded 10a (68 $\mathrm{mg}, 55 \%)$ as a colorless oil: ${ }^{1} \mathrm{H}$ NMR $\left(250 \mathrm{MHz}, \mathrm{CDCl}_{3}\right): \delta=6.10(\mathrm{dd}, J=6.1,0.7 \mathrm{~Hz}, 1 \mathrm{H}), 5.56(\mathrm{dd}, J=6.1,0.5$ $\mathrm{Hz}, 1 \mathrm{H}), 4.12(\mathrm{~m}, 4 \mathrm{H}), 2.50(\mathrm{~m}, 1 \mathrm{H}), 2.22(\mathrm{~m}, 2 \mathrm{H}), 1.97(\mathrm{~m}, 3 \mathrm{H}), 1.22(\mathrm{t}, J$ $=7.1 \mathrm{~Hz}, 6 \mathrm{H}) ;{ }^{13} \mathrm{C} \mathrm{NMR}\left(62.9 \mathrm{MHz}, \mathrm{CDCl}_{3}\right): \delta=173.6,172.3,125.6$, $124.9,71.7,71.6,61.4,61.0,41.0,39.2,24.7,13.9,13.8$; IR (KBr): $v=$ $1727 \mathrm{~cm}^{-1}$; elemental analysis calcd $(\%)$ for $\mathrm{C}_{13} \mathrm{H}_{18} \mathrm{O}_{4} \mathrm{~S}$ : C 57.76, H 6.71, S 11.86; found: C 57.43, H 7.10, S 11.56.

Diethyl 3a,4,5,6,7,7a-hexahydrobenzo $[b]$ thiophene-3a,7a-dicarboxylate (10b). A $-78^{\circ} \mathrm{C}$ solution of $\mathrm{Me}_{3} \mathrm{SnLi}$ in THF was treated with $\mathbf{8}^{[19]}$ (100 $\mathrm{mg}, 0.44 \mathrm{mmol})$ in THF and stirred for $1 \mathrm{~h} .1$,4-Diiodobutane $(70 \mu \mathrm{L}, 0.53$ mmol) was added and the mixture stirred for $1 \mathrm{~h}$ at $-78^{\circ} \mathrm{C}$, and then for 14 $\mathrm{h}$ while slowly warming up to room temperature. Work-up as for 9a afforded 10b (75 mg, 60\%) as a colorless oil: ${ }^{1} \mathrm{H}$ NMR (250 MHz, $\left.\mathrm{CDCl}_{3}\right)$ : $\delta=5.99(\mathrm{~d}, J=6.3 \mathrm{~Hz}, 1 \mathrm{H}), 5.95(\mathrm{~d}, J=6.3 \mathrm{~Hz}, 1 \mathrm{H}), 4.13$ (quint, $J=7.1$ $\mathrm{Hz}, 4 \mathrm{H}), 2.18(\mathrm{~m}, 2 \mathrm{H}), 2.00(\mathrm{~m}, 1 \mathrm{H}), 1.69(\mathrm{~m}, 3 \mathrm{H}), 1.48(\mathrm{~m}, 1 \mathrm{H}), 1.33(\mathrm{~m}$, $1 \mathrm{H}), 1.22$ (q, $J=7.2 \mathrm{~Hz}, 6 \mathrm{H}) ;{ }^{13} \mathrm{C} \mathrm{NMR}\left(62.9 \mathrm{MHz}, \mathrm{CDCl}_{3}\right): \delta=173.1$, $172.9,130.9,121.7,63.0,61.2,60.8,59.8,33.7,28.9,21.1,19.4,14.1$, 13.9; IR (KBr): $v=1729 \mathrm{~cm}^{-1}$; HRMS (ESI): $m / z$ calcd for $\mathrm{C}_{14} \mathrm{H}_{20} \mathrm{O}_{4} \mathrm{SNa}$ : 
$307.0975\left[\mathrm{M}^{+\mathrm{Na}^{+}}\right]$; found: 307.0981 ; elemental analysis calcd (\%) for $\mathrm{C}_{14} \mathrm{H}_{20} \mathrm{O}_{4} \mathrm{~S}$ : C 59.13, H 7.09, S 11.28; found: C 58.78, H 7.07, S 11.04. Diethyl 3a,4,7,7a-tetrahydrobenzo[ $b]$ thiophene-3a,7a-dicarboxylate (10c). A $-78{ }^{\circ} \mathrm{C}$ solution of $\mathrm{Me}_{3} \mathrm{SnLi}$ in THF was treated with $8^{[19]}(92 \mathrm{mg}$, $0.40 \mathrm{mmol})$ in THF and stirred for $1 \mathrm{~h}$. cis-1,4-Dichloro-2-butene $(50 \mu \mathrm{L}$, $0.48 \mathrm{mmol}$ ) was added and the mixture stirred for $1 \mathrm{~h}$ at $-78^{\circ} \mathrm{C}$, then slowly allowed to reach r.t. for $14 \mathrm{~h}$, and heated at $30^{\circ} \mathrm{C}$ for $3 \mathrm{~h}$. Work-up as for $9 \mathbf{a}$ afforded $10 \mathrm{c}$ as a colorless oil (59 mg, $52 \%)$ : ${ }^{1} \mathrm{H}$ NMR $(500 \mathrm{MHz}$, $\left.\mathrm{CDCl}_{3}\right): \delta=6.05(\mathrm{~d}, J=6.3 \mathrm{~Hz}, 1 \mathrm{H}), 6.03(\mathrm{~d}, J=6.3 \mathrm{~Hz}, 1 \mathrm{H}), 5.86(\mathrm{~m}, 1 \mathrm{H})$, $5.77(\mathrm{~m}, 1 \mathrm{H}), 4.14(\mathrm{~m}, 4 \mathrm{H}), 2.84$ (dquint, $J=19.0,2.6 \mathrm{~Hz}, 1 \mathrm{H}), 2.74(\mathrm{~m}$, $1 \mathrm{H}), 2.49(\mathrm{~m}, 2 \mathrm{H}), 1.22(\mathrm{q}, J=7.3 \mathrm{~Hz}, 6 \mathrm{H}) ;{ }^{13} \mathrm{C} \mathrm{NMR}\left(62.9 \mathrm{MHz}, \mathrm{CDCl}_{3}\right)$ : $\delta=172.9,172.5,131.6,124.7,124.4,122.8,61.7,61.4,60.9,58.0,34.0$, $30.5,13.9,13.8$; IR (KBr): $v=1730 \mathrm{~cm}^{-1}$; elemental analysis calcd (\%) for $\mathrm{C}_{14} \mathrm{H}_{18} \mathrm{O}_{4} \mathrm{~S}: \mathrm{C} 59.55, \mathrm{H} 6.43$, S 11.36; found: C 59.78, H 6.63, S 11.32. Diisopropyl benzofuran-2,3-dicarboxylate (11). Toluene $(25 \mathrm{~mL})$ was added to a solution of benzofuran-2,3-dicarboxylic acid (1 g, $4.85 \mathrm{mmol})$ in $i$ PrOH $(25 \mathrm{~mL})$ in the presence of $\mathrm{H}_{2} \mathrm{SO}_{4}(150 \mu \mathrm{L})$, and the mixture was refluxed using a Dean-Stark trap. During the first 6 hours, $6 \mathrm{~mL}$ were withdrawn every hour and replenished by an equal volume of the $i \mathrm{PrOH}-$ toluene mixture. After 36 hours, the solution was evaporated under reduced pressure to $5 \mathrm{~mL}$, diluted with $\mathrm{CH}_{2} \mathrm{Cl}_{2}(20 \mathrm{~mL})$ and neutralized with cold, saturated $\mathrm{NaHCO}_{3}$. The organic layer was washed with brine, dried and concentrated. The residue was purified by bulb-to-bulb distillation to yield 11 as a colorless oil $(1.21 \mathrm{~g}, 86 \%):{ }^{1} \mathrm{H}$ NMR $\left(250 \mathrm{MHz}, \mathrm{CDCl}_{3}\right): \delta=7.85$ $(\mathrm{d}, J=7.8 \mathrm{~Hz}, 1 \mathrm{H}), 7.56(\mathrm{~d}, J=8.3 \mathrm{~Hz}, 1 \mathrm{H}), 7.45(\mathrm{~m}, 1 \mathrm{H}), 7.35(\mathrm{~m}, 1 \mathrm{H})$, $5.33(\mathrm{~m}, 2 \mathrm{H}), 1.42(\mathrm{~d}, J=6.3 \mathrm{~Hz}, 6 \mathrm{H}), 1.40(\mathrm{~d}, J=6.3 \mathrm{~Hz}, 6 \mathrm{H}) ;{ }^{13} \mathrm{C} \mathrm{NMR}$ $\left(62.9 \mathrm{MHz}, \mathrm{CDCl}_{3}\right): \delta=162.0,158.3,153.9,145.7,127.7,125.4,124.4$, 122.5, 118.3, 112.1, 70.1, 69.3, 21.8, 21.7; IR $\left(\mathrm{CHCl}_{3}\right): v=1728 \mathrm{~cm}^{-1}$; HRMS (ESI): $m / z$ calcd for $\mathrm{C}_{16} \mathrm{H}_{19} \mathrm{O}_{5}: 291.1227\left[M+\mathrm{H}^{+}\right]$; found: 291.1232; elemental analysis calcd (\%) for $\mathrm{C}_{16} \mathrm{H}_{18} \mathrm{O}_{5}: \mathrm{C} 66.19, \mathrm{H}$ 6.25; found: $\mathrm{C} 66.22$, H 6.52 .

Diisopropyl 2,3,3a,8b-tetrahydro- $1 H$-benzo $[b]$ cyclopenta $[\boldsymbol{d}]$ furan3a,8b-dicarboxylate (12a). A $-78^{\circ} \mathrm{C}$ solution of $\mathrm{Me}_{3} \mathrm{SnLi}$ in THF was treated with a solution of $\mathbf{1 1}(110 \mathrm{mg}, 0.38 \mathrm{mmol})$ in THF $(2 \mathrm{~mL})$, warmed to $-55^{\circ} \mathrm{C}$ and stirred for $1 \mathrm{~h}$. 1,3-Diiodopropane $(50 \mu \mathrm{L}, 0.44 \mathrm{mmol})$ was added and the mixture stirred for $15 \mathrm{~h}$ while slowly warming to room temperature, and then heated at $30^{\circ} \mathrm{C}$ for $3 \mathrm{~h}$. The reaction was quenched by adding $\mathrm{pH} 5.6$ acetate buffer and then partitioned between $\mathrm{CH}_{2} \mathrm{Cl}_{2}$ and acetate buffer. The aqueous layer was extracted with $\mathrm{CH}_{2} \mathrm{Cl}_{2}$ and the combined organic extracts were washed with brine, dried $\left(\mathrm{Na}_{2} \mathrm{SO}_{4}\right)$, and concentrated. The residue was purified by column chromatography $\left(\mathrm{Al}_{2} \mathrm{O}_{3}\right.$, $\mathrm{CH}_{2} \mathrm{Cl}_{2}$ hexane 3:1) to give $88 \mathrm{mg}(70 \%)$ of 12a as a white solid: m.p. $82-$ $85^{\circ} \mathrm{C}(\mathrm{EtOH}) ;{ }^{1} \mathrm{H}$ NMR $\left(250 \mathrm{MHz}, \mathrm{CDCl}_{3}\right): \delta=7.12(\mathrm{~m}, 2 \mathrm{H}), 6.86(\mathrm{~m}$, 2H), 5.03 (hept, $J=6.3 \mathrm{~Hz}, 1 \mathrm{H}$ ), 4.91 (hept, $J=6.3 \mathrm{~Hz}, 1 \mathrm{H}$ ), 2.48 (td, $J=$ $12.8,6.4 \mathrm{~Hz}, 1 \mathrm{H}), 2.26(\mathrm{~m}, 3 \mathrm{H}), 1.83(\mathrm{~m}, 1 \mathrm{H}), 1.49(\mathrm{~m}, 1 \mathrm{H}), 1.24(\mathrm{~d}, J=$ $6.1 \mathrm{~Hz}, 3 \mathrm{H}), 1.22(\mathrm{~d}, J=6.1 \mathrm{~Hz}, 3 \mathrm{H}), 1.13(\mathrm{~d}, J=6.3 \mathrm{~Hz}, 3 \mathrm{H}), 1.07$ (d, $J=$ $6.3 \mathrm{~Hz}, 3 \mathrm{H}) ;{ }^{13} \mathrm{C} \mathrm{NMR}\left(62.9 \mathrm{MHz}, \mathrm{CDCl}_{3}\right): \delta=171.0,170.4,159.4,129.2$, $128.9,123.3,121.2,109.8,98.5,69.1,68.8,67.8,40.4,38.3,23.8,21.6$, 21.5, 21.32, 21.31; IR $\left(\mathrm{CHCl}_{3}\right): v=1734 \mathrm{~cm}^{-1}$; HRMS (ESI): $\mathrm{m} / z$ calcd for $\mathrm{C}_{19} \mathrm{H}_{25} \mathrm{O}_{5}: 333.1693\left[M+\mathrm{H}^{+}\right]$; found: 333.1699 ; elemental analysis calcd (\%) for $\mathrm{C}_{19} \mathrm{H}_{24} \mathrm{O}_{5}$ : C 68.66, H 7.28; found: C 68.38, H 7.68.

Diisopropyl 1,2,3,4,4a,9b-hexahydrodibenzo $[\boldsymbol{b}, \boldsymbol{d}]$ furan-4a,9b-

dicarboxylate (12b). Using the same procedure as for 12a, except that 1,4diiodobutane ( $60 \mu \mathrm{L}, 0.45 \mathrm{mmol}$ ) was used as the electrophile, 12b was obtained as a white solid ( $89 \mathrm{mg}, 68 \%)$ : $\mathrm{mp} 84-86{ }^{\circ} \mathrm{C}(\mathrm{EtOH}) ;{ }^{1} \mathrm{H}$ NMR (250 MHz, $\mathrm{CD}_{2} \mathrm{Cl}_{2}$ ): $\delta=7.20(\mathrm{~m}, 2 \mathrm{H}), 6.92(\mathrm{td}, J=7.6,0.9 \mathrm{~Hz}, 1 \mathrm{H}), 6.86$ (d, $J=8.0 \mathrm{~Hz}, 1 \mathrm{H}$ ), 5.06 (hept, $J=6.3 \mathrm{~Hz}, 1 \mathrm{H}$ ), 4.83 (hept, $J=6.2 \mathrm{~Hz}, 1 \mathrm{H}$ ), $2.42(\mathrm{dt}, J=14.2,4.1 \mathrm{~Hz}, 1 \mathrm{H}), 2.14(\mathrm{~m}, 2 \mathrm{H}), 1.70(\mathrm{~m}, 2 \mathrm{H}), 1.51(\mathrm{~m}, 3 \mathrm{H})$, 1.27 (d, $J=6.3 \mathrm{~Hz}, 3 \mathrm{H}), 1.23$ (d, $J=6.3 \mathrm{~Hz}, 3 \mathrm{H}), 1.09$ (d, $J=6.2 \mathrm{~Hz}, 3 \mathrm{H})$, $1.08(\mathrm{~d}, J=6.2 \mathrm{~Hz}, 3 \mathrm{H}) .{ }^{13} \mathrm{C}$ NMR $\left(62.9 \mathrm{MHz}, \mathrm{CDCl}_{3}\right): \delta=171.7,170.5$, 157.6, 129.3, 129.0, 123.4, 121.1, 111.3, 89.7, 68.8, 68.5, 57.1, 33.2, 29.2, 21.7, 21.5, 21.3, 21.2, 20.7, 20.3; HRMS (ESI): $\mathrm{m} / \mathrm{z}$ calcd for $\mathrm{C}_{20} \mathrm{H}_{26} \mathrm{O}_{5}+\mathrm{Na}^{+}: 369.1672\left[M+\mathrm{Na}^{+}\right]$; found: 369.1678 .
Diisopropyl 6,7,8,9,10,10a-hexahydro-5a $H$-benzo $[b]$ cyclohepta $[d]$ furan5a,10a-dicarboxylate (12c). A $-78{ }^{\circ} \mathrm{C}$ solution of $\mathrm{Me}_{3} \mathrm{SnLi}$ in THF was treated with a solution of $\mathbf{1 1}(102 \mathrm{mg}, 0.35 \mathrm{mmol})$ in THF, then warmed to $-55^{\circ} \mathrm{C}$ and stirred for $1.5 \mathrm{~h}$. 1,5-Diiodopentane $(60 \mu \mathrm{L}, 0.40 \mathrm{mmol})$ in DMF $(1.2 \mathrm{ml})$ was added, and the mixture stirred for $8 \mathrm{~h}$ while slowly warming to room temperature, and then heated at $45{ }^{\circ} \mathrm{C}$ for $14 \mathrm{~h}$. Work-up as for 12a and purification by column chromatography (neutral $\mathrm{Al}_{2} \mathrm{O}_{3}$, $\mathrm{CH}_{2} \mathrm{Cl}_{2} / \mathrm{Hex}$ 1:2) afforded $75 \mathrm{mg}$ (59\%) of 12c as a white solid: mp 81-84 ${ }^{\circ} \mathrm{C}(\mathrm{EtOH}) ;{ }^{1} \mathrm{H}$ NMR $\left(250 \mathrm{MHz}, \mathrm{CD}_{2} \mathrm{Cl}_{2}\right): \delta=7.16(\mathrm{~m}, 2 \mathrm{H}), 6.89$ (td, $J=$ 7.5, $1.0 \mathrm{~Hz}, 1 \mathrm{H}), 6.83(\mathrm{~d}, J=8.0 \mathrm{~Hz}, 1 \mathrm{H}), 4.90(\mathrm{~m}, 2 \mathrm{H}), 2.41-2.03(\mathrm{~m}, 4 \mathrm{H})$, 1.73-1.12 (m, 15H), $1.04(\mathrm{~d}, J=6.2 \mathrm{~Hz}, 3 \mathrm{H}) ;{ }^{13} \mathrm{C}$ NMR $(62.9 \mathrm{MHz}$, $\mathrm{CD}_{2} \mathrm{Cl}_{2}$ ): $\delta=173.0,171.4,158.9,130.6,129.5,124.9,121.1,109.7,95.4$, 69.4, 69.3, 63.7, 36.4, 35.4, 31.2, 25.0, 23.2, 21.8, 21.7, 21.6, 21.5; IR (KBr): $v=1734 \mathrm{~cm}^{-1}$; HRMS (ESI): $m / z$ calcd for $\mathrm{C}_{21} \mathrm{H}_{29} \mathrm{O}_{5}: 361.2010$ $\left[M+\mathrm{H}^{+}\right]$; found: 361.2010 ; elemental analysis calcd (\%) for $\mathrm{C}_{21} \mathrm{H}_{28} \mathrm{O}_{5}: \mathrm{C}$ 69.98, H 7.83; found: C 69.58, H 7.82.

Diisopropyl 1,4,4a,9b-tetrahydrodibenzo $[b, d]$ furan-4a,9b-dicarboxylate (12d). Compound 12d was prepared following the same procedure as for 12a. Thus, 11 (120 mg, $0.41 \mathrm{mmol})$ and cis-1,4-dichloro-2-butene $(50 \mu \mathrm{L}$, $0.48 \mathrm{mmol}$ ) afforded $85 \mathrm{mg}$ of $\mathbf{1 2 d}(60 \%)$ as a white solid, after work-up and purification by column chromatography (neutral $\mathrm{Al}_{2} \mathrm{O}_{3}, \mathrm{CH}_{2} \mathrm{Cl}_{2} / \mathrm{Hex}$ 1:1): $\mathrm{mp} 79-81{ }^{\circ} \mathrm{C}(\mathrm{EtOH}) ;{ }^{1} \mathrm{H}$ NMR $\left(250 \mathrm{MHz}, \mathrm{CDCl}_{3}\right): \delta=7.11(\mathrm{~m}, 2 \mathrm{H})$, $6.82(\mathrm{~m}, 2 \mathrm{H}), 5.79(\mathrm{~m}, 2 \mathrm{H}), 5.04$ (hept, $J=6.3 \mathrm{~Hz}, 1 \mathrm{H}), 4.91$ (hept, $J=6.3$ $\mathrm{Hz}, 1 \mathrm{H}), 2.73(\mathrm{~m}, 4 \mathrm{H}), 1.23(\mathrm{~d}, J=6.3 \mathrm{~Hz}, 3 \mathrm{H}), 1.21(\mathrm{~d}, J=6.3 \mathrm{~Hz}, 3 \mathrm{H})$, $1.13(\mathrm{~d}, J=6.3 \mathrm{~Hz}, 3 \mathrm{H}), 1.07(\mathrm{~d}, J=6.3 \mathrm{~Hz}, 3 \mathrm{H}) ;{ }^{13} \mathrm{C} \mathrm{NMR}(62.9 \mathrm{MHz}$, $\left.\mathrm{CDCl}_{3}\right): \delta=171.5,170.5,159.1,129.8,129.1,126.7,125.4,123.3,121.0$, 109.9, 91.7, 69.1, 69.0, 59.4, 33.9, 31.7, 21.5, 21.4, 21.2; IR (KBr): $v=$ $1762,1725 \mathrm{~cm}^{-1}$; elemental analysis calcd (\%) for $\mathrm{C}_{20} \mathrm{H}_{24} \mathrm{O}_{5}: \mathrm{C} 69.75, \mathrm{H}$ 7.02; found: C 69.45, H 7.02.

Diisopropyl naphthalene-1,4-dicarboxylate (13). A suspension of naphthalene-1,4-dicarboxylic acid (1.0 g, $4.62 \mathrm{mmol})$ and benzyltriethylamonium chloride $(25 \mathrm{mg}, 0.11 \mathrm{mmol}$ ) in 1,2-dichloroethane $(8 \mathrm{~mL})$ was heated to reflux and then treated with $\mathrm{SOCl}_{2}(870 \mu \mathrm{L}, 12$ $\mathrm{mmol})$. The reaction mixture was refluxed for $12 \mathrm{~h}$, hot filtered, and the filtrate concentrated. The residue was dried under vacuum in the presence of $\mathrm{NaOH}$ pellets. The crude acid chloride was dissolved in $\mathrm{CH}_{2} \mathrm{Cl}_{2}(24 \mathrm{~mL})$, DMAP $(56 \mathrm{mg}, 0.46 \mathrm{mmol})$ and $i \mathrm{PrOH}(1.5 \mathrm{~mL}, 19 \mathrm{mmol})$ were added, and the resulting solution was cooled down to $0{ }^{\circ} \mathrm{C}$ and treated with $\mathrm{Et}_{3} \mathrm{~N}(2.7$ $\mathrm{mL}, 19 \mathrm{mmol}$ ). The reaction mixture was stirred for $15 \mathrm{~min}$ at $0{ }^{\circ} \mathrm{C}$ and at room temperature for $4 \mathrm{~h}$. Then it was washed with $\mathrm{HCl} 2 \mathrm{M}$ and water, and the organic layer was dried and concentrated. Column chromatography (EtOAc/Hexane 1:20) afforded $1.18 \mathrm{~g}$ of $\mathbf{1 3}$ (85\% yield) as a white solid: mp 69-70 ${ }^{\circ} \mathrm{C}\left(\mathrm{CH}_{2} \mathrm{Cl}_{2}\right.$-hexane); ${ }^{1} \mathrm{H}$ NMR $\left(250 \mathrm{MHz}, \mathrm{CDCl}_{3}\right): \delta=8.78$ (dd, $J=6.7,3.4 \mathrm{~Hz}, 2 \mathrm{H}), 8.02(\mathrm{~s}, 2 \mathrm{H}), 7,61$ (dd, $J=6.7,3.4 \mathrm{~Hz}, 2 \mathrm{H}), 5.37$ (hept, $J=6.3 \mathrm{~Hz}, 2 \mathrm{H}), 1.43(\mathrm{~d}, J=6.3 \mathrm{~Hz}, 12 \mathrm{H}) ;{ }^{13} \mathrm{C} \mathrm{NMR}\left(62.9 \mathrm{MHz}, \mathrm{CDCl}_{3}\right)$ : $\delta=166.9,132.3,131.3,127.6,127.5,125.9,69.1,21.9 ; \mathrm{IR}(\mathrm{KBr}): v=1713$ $\mathrm{cm}^{-1}$; elemental analysis calcd (\%) for $\mathrm{C}_{18} \mathrm{H}_{20} \mathrm{O}_{4}$ : C 71.98, H 6.71; found: $\mathrm{C}$ 71.78, H 7.01

\section{Diisopropyl naphthalene-2,6-dicarboxylate (14). Using the same} procedure as for 13, naphthalene-2,6-dicarboxylic acid (500 mg, $2.3 \mathrm{mmol}$ ) afforded $615 \mathrm{mg}$ of $\mathbf{1 4}$ (89\% yield): $\mathrm{mp} 118-120{ }^{\circ} \mathrm{C}\left(\mathrm{CH}_{2} \mathrm{Cl}_{2}\right.$-hexane); ${ }^{1} \mathrm{H}$ $\operatorname{NMR}\left(250 \mathrm{MHz}, \mathrm{CDCl}_{3}\right): \delta=8.59(\mathrm{~s}, 2 \mathrm{H}), 8.10(\mathrm{dd}, J=8.5,1.0 \mathrm{~Hz}, 2 \mathrm{H})$, $7.98(\mathrm{~d}, J=8.5 \mathrm{~Hz}, 2 \mathrm{H}), 5.31$ (hept, $J=6.2 \mathrm{~Hz}, 2 \mathrm{H}), 1.41$ (d, $J=6.2 \mathrm{~Hz}$, $12 \mathrm{H}) ;{ }^{13} \mathrm{C}$ NMR (62.9 MHz, $\left.\mathrm{CDCl}_{3}\right): \delta=165.9,134.5,130.4,130.1,129.4$, 126.0, 68.8, 22.0; IR (KBr): $v=1708 \mathrm{~cm}^{-1}$; elemental analysis calcd (\%) for $\mathrm{C}_{18} \mathrm{H}_{20} \mathrm{O}_{4}$ : C 71.98, H 6.71; found: C 71.70, H 7.00.

Diisopropyl 2,3,3a,9b-tetrahydro- $\boldsymbol{H}$-cyclopenta $[\boldsymbol{a}]$ naphthalene-5,9bdicarboxylate (15a). A $-78^{\circ} \mathrm{C}$ solution of $\mathrm{Me}_{3} \mathrm{SnLi}(0.77 \mathrm{mmol})$ in $\mathrm{THF}$ was treated with a solution of $\mathbf{1 3}$ (109 $\mathrm{mg}, 0.36 \mathrm{mmol})$ in THF $(2 \mathrm{~mL})$. After stirring for $4 \mathrm{~h}, 1,3$-dibromopropane ( $40 \mu \mathrm{L}, 0.40 \mathrm{mmol})$ was added and the resulting mixture was stirred for $2 \mathrm{~h}$ at $-78^{\circ} \mathrm{C}$ and then for $18 \mathrm{~h}$ while slowly warming to room temperature. The reaction was quenched with $\mathrm{pH} 7.0$ phosphate buffer $(0.2 \mathrm{~mL})$, and then partitioned between 
$\mathrm{CH}_{2} \mathrm{Cl}_{2}$ and phosphate buffer. The aqueous phase was extracted with $\mathrm{CH}_{2} \mathrm{Cl}_{2}$ and the combined organic phase was washed with brine, dried and concentrated. The residue was purified by column chromatography (70-230 $\mathrm{SiO}_{2}$, EtOAc/hexane 1:20) to give 15a as a colorless oil (108 mg, 87\%): ${ }^{1} \mathrm{H}$ NMR (250 MHz, $\left.\mathrm{CD}_{2} \mathrm{Cl}_{2}\right): \delta=7.83(\mathrm{~m}, 1 \mathrm{H}), 7.24(\mathrm{~m}, 3 \mathrm{H}), 6.82(\mathrm{~d}, J=4.7$ $\mathrm{Hz}, 1 \mathrm{H}), 5.17$ (hept, $J=6.3 \mathrm{~Hz}, 1 \mathrm{H}), 4.95$ (hept, $J=6.3 \mathrm{~Hz}, 1 \mathrm{H}), 3.31$ (m, $1 \mathrm{H}), 2.57(\mathrm{~m}, 1 \mathrm{H}), 2.04(\mathrm{~m}, 2 \mathrm{H}), 1.63(\mathrm{~m}, 3 \mathrm{H}), 1.33(\mathrm{~d}, J=6.3 \mathrm{~Hz}, 6 \mathrm{H})$, $1.16(\mathrm{~d}, J=6.2 \mathrm{~Hz}, 3 \mathrm{H}), 1.14(\mathrm{~d}, J=6.2 \mathrm{~Hz}, 3 \mathrm{H}) ;{ }^{13} \mathrm{C} \mathrm{NMR}(62.9 \mathrm{MHz}$, $\left.\mathrm{CD}_{2} \mathrm{Cl}_{2}\right): \delta=175.1,166.8,140.4,136.8,129.1,129.0,128.5,127.5,127.3$, 126.7, 69.0, 68.6, 56.7, 43.8, 38.6, 33.0, 23.3, 22.2, 21.8, 21.7; IR (KBr): $v$ $=1717 \mathrm{~cm}^{-1}$; elemental analysis calcd $(\%)$ for $\mathrm{C}_{21} \mathrm{H}_{26} \mathrm{O}_{4}: \mathrm{C} 73.66, \mathrm{H} 7.65$; found: C 73.91, H 7.82.

\section{Diisopropyl 6a,7,12,12a-tetrahydrotetraphene-5,12a-dicarboxylate}

(15b). Using the same procedure as for $\mathbf{1 5 a}$, except that 1,2-ortho-

dichloroxylene ( $65 \mathrm{mg}, 0.37 \mathrm{mmol}$ ) was used as the electrophile, $101 \mathrm{mg}$ of $13(0.34 \mathrm{mmol})$ afforded $82 \mathrm{mg}$ of $\mathbf{1 5 b}(60 \%)$ as a colorless oil: ${ }^{1} \mathrm{H}$ NMR $\left(250 \mathrm{MHz}, \mathrm{CD}_{2} \mathrm{Cl}_{2}\right): \delta=7.86(\mathrm{~m}, 1 \mathrm{H}), 7.29(\mathrm{~m}, 2 \mathrm{H}), 7.12(\mathrm{~m}, 5 \mathrm{H}), 6.92(\mathrm{~d}$, $J=3.4 \mathrm{~Hz}, 1 \mathrm{H}), 5.11$ (hept, $J=6.3 \mathrm{~Hz}, 2 \mathrm{H}), 3.56(\mathrm{~m}, 1 \mathrm{H}), 3.26(\mathrm{~d}, J=16.9$ $\mathrm{Hz}, 1 \mathrm{H}), 3.07$ (m, 2H), $2.85(\mathrm{dd}, J=17.4,3.8 \mathrm{~Hz}, 1 \mathrm{H}), 1.31(\mathrm{~d}, J=6.2 \mathrm{~Hz}$, $6 \mathrm{H}), 1.22(\mathrm{~d}, J=6.3 \mathrm{~Hz}, 3 \mathrm{H}), 1.14(\mathrm{~d}, J=6.3 \mathrm{~Hz}, 3 \mathrm{H}) .{ }^{13} \mathrm{C}$ NMR $(62.9$ $\left.\mathrm{MHz}, \mathrm{CD}_{2} \mathrm{Cl}_{2}\right): \delta=174.6,165.9,143.3,138.9,136.7,133.9,131.6,130.2$, $129.6,129.0,128.8,127.7,127.5,126.4,126.3,125.7,69.4,68.9,50.8$, $36.6,34.2,31.7,22.2,22.1,22.0,21.7$; IR (KBr): $v=1756 \mathrm{~cm}^{-1}$; HRMS (ESI): $m / z$ calcd for $\mathrm{C}_{26} \mathrm{H}_{29} \mathrm{O}_{4}: 405.2066\left[M+\mathrm{H}^{+}\right]$; found: 405.2102 .

\section{Diisopropyl 2,3,3a,9b-tetrahydro-1 $H$-cyclopenta $[a]$ naphthalene-3a,7-} dicarboxylate (16a). Following the same procedure as for 15a, starting from 14 (103 mg, $0.34 \mathrm{mmol}$ ) and using 1,3-dibromopropane ( $40 \mu \mathrm{L}, 0.39$ $\mathrm{mmol})$ as the electrophile, 16a was obtained as a colorless oil (93 $\mathrm{mg}$, 79\%): ${ }^{1} \mathrm{H}$ NMR (250 MHz, $\mathrm{CD}_{2} \mathrm{Cl}_{2}$ ): $\delta=7.80(\mathrm{dd}, J=7.8,1.6 \mathrm{~Hz}, 1 \mathrm{H})$, $7.73(\mathrm{~s}, 1 \mathrm{H}), 7.23(\mathrm{~d}, J=7.8 \mathrm{~Hz}, 1 \mathrm{H}), 6.49(\mathrm{~d}, J=9.6 \mathrm{~Hz}, 1 \mathrm{H}), 5.81(\mathrm{~d}, J=$ $9.6 \mathrm{~Hz}, 1 \mathrm{H}$ ), 5.19 (hept, $J=6.3 \mathrm{~Hz}, 1 \mathrm{H}$ ), 4.88 (hept, $J=6.3 \mathrm{~Hz}, 1 \mathrm{H}$ ), 3.61 $(\mathrm{t}, J=9.1 \mathrm{~Hz}, 1 \mathrm{H}), 2.41-2.10(\mathrm{~m}, 2 \mathrm{H}), 2.01(\mathrm{~m}, 1 \mathrm{H}), 1.62(\mathrm{~m}, 3 \mathrm{H}), 1.34(\mathrm{~d}$, $J=6.2 \mathrm{~Hz}, 6 \mathrm{H}), 1.13(\mathrm{t}, J=6.7 \mathrm{~Hz}, 6 \mathrm{H}) ;{ }^{13} \mathrm{C} \mathrm{NMR}\left(62.9 \mathrm{MHz}, \mathrm{CD}_{2} \mathrm{Cl}_{2}\right)$ : $\delta=174.8,166.3,143.5,131.3,131.1,129.8,129.0,128.4,128.1,126.4$, $68.7,68.5,53.5,45.9,40.2,37.0,23.9,22.2,21.88,21.85$; IR (KBr): $v=$ $1717 \mathrm{~cm}^{-1}$; elemental analysis calcd $(\%)$ for $\mathrm{C}_{21} \mathrm{H}_{26} \mathrm{O}_{4}$ : C 73.66, H 7.65; found: C 73.56, H 8.00.

Diisopropyl 4b,5,6,7,8,8a-hexahydrophenanthrene-2,8a-dicarboxylate (16b). Following the same procedure as for 15a, but starting from 14 (92 $\mathrm{mg}, 0.31 \mathrm{mmol})$ and using 1.4-diiodobutane $(46 \mu \mathrm{L}, 0.35 \mathrm{mmol})$ as the electrophile, $16 \mathbf{b}$ was obtained in $66 \%$ yield $(72 \mathrm{mg})$ as a colorless oil: ${ }^{1} \mathrm{H}$ NMR $\left(250 \mathrm{MHz}, \mathrm{CD}_{2} \mathrm{Cl}_{2}\right): \delta=7.80(\mathrm{dd}, J=7.8,1.7 \mathrm{~Hz}, 1 \mathrm{H}), 7.69(\mathrm{~d}, J=$ $1.7 \mathrm{~Hz}, 1 \mathrm{H}), 7.19$ (d, $J=7.8 \mathrm{~Hz}, 1 \mathrm{H}), 6.60$ (d, $J=9.5 \mathrm{~Hz}, 1 \mathrm{H}), 5.78$ (dd, $J=$ 9.5, $1.0 \mathrm{~Hz}, 1 \mathrm{H}$ ), 5.19 (hept, $J=6.3 \mathrm{~Hz}, 1 \mathrm{H}$ ), 4.77 (hept, $J=6.3 \mathrm{~Hz}, 1 \mathrm{H}$ ), $3.22(\mathrm{~m}, 1 \mathrm{H}), 2.00(\mathrm{~m}, 1 \mathrm{H}), 1.63(\mathrm{~m}, 3 \mathrm{H}), 1.39(\mathrm{~m}, 4 \mathrm{H}), 1.33(\mathrm{~d}, J=6.3 \mathrm{~Hz}$, $6 \mathrm{H}), 1.04(\mathrm{~d}, J=6.3 \mathrm{~Hz}, 3 \mathrm{H}), 1.03(\mathrm{~d}, J=6.3 \mathrm{~Hz}, 3 \mathrm{H}) ;{ }^{13} \mathrm{C} \mathrm{NMR}(62.9$ $\left.\mathrm{MHz}, \mathrm{CD}_{2} \mathrm{Cl}_{2}\right): \delta=175.0,166.3,146.2,132.3,132.1,129.8,129.3,128.5$, $127.8,127.7,68.6,68.2,47.9,42.4,34.5,30.3,24.6,22.5,22.2,21.75$, 21.74; IR (KBr): $v=1716 \mathrm{~cm}^{-1}$; elemental analysis calcd $(\%)$ for $\mathrm{C}_{22} \mathrm{H}_{28} \mathrm{O}_{4}$ : C 74.13, H 7.92; found: C 73.87, H 7.56.

((4bS,8aS)-4b,5,6,7,8,8a-hexahydrophenanthrene-2,8a-diyl)dimethanol (16c). A $0{ }^{\circ} \mathrm{C}$ suspension of $\mathrm{LiAlH}_{4}(20 \mathrm{mg}, 0.53 \mathrm{mmol})$ in THF $(1 \mathrm{~mL})$ was treated with a solution of $\mathbf{1 6 b}(90 \mathrm{mg}, 0.25 \mathrm{mmol})$ in THF $(1 \mathrm{~mL})$. The reaction mixture was stirred for $12 \mathrm{~h}$ while slowly warming to room temperature. After cooling down to $0{ }^{\circ} \mathrm{C}$, EtOAc $(1 \mathrm{~mL})$ was carefully added, followed by $\mathrm{CHCl}_{3}$, saturated aqueous $\mathrm{Na}_{2} \mathrm{CO}_{3}$, solid $\mathrm{KH}_{2} \mathrm{PO}_{4}$ and $\mathrm{Na}_{2} \mathrm{SO}_{4}$. The resulting suspension was stirred at room temperature for $1 \mathrm{~h}$, then filtered over celite and evaporated. The product was obtained as white crystals after crystallization from $\mathrm{CH}_{2} \mathrm{Cl}_{2}$ /hexanes (47 mg, 77\%): mp 100$101{ }^{\circ} \mathrm{C} ;{ }^{1} \mathrm{H}$ NMR $\left(250 \mathrm{MHz}, \mathrm{CDCl}_{3}\right): \delta=7.11(\mathrm{dd}, J=7.6,1.5 \mathrm{~Hz}, 1 \mathrm{H})$, $7.04(\mathrm{~m}, 2 \mathrm{H}), 6.52(\mathrm{~d}, J=9.6 \mathrm{~Hz}, 1 \mathrm{H}), 5.58(\mathrm{dd}, J=9.6,1.3 \mathrm{~Hz}, 1 \mathrm{H}), 4.59$ $(\mathrm{s}, 2 \mathrm{H}), 3.28(\mathrm{~d}, J=10.7 \mathrm{~Hz}, 1 \mathrm{H}), 3.14(\mathrm{~d}, J=10.7 \mathrm{~Hz}, 1 \mathrm{H}), 2.60$ (dd, $J=$ 11.8, $3.8 \mathrm{~Hz}, 1 \mathrm{H}), 1.86$ (br s, $1 \mathrm{H}), 1.71-1.18$ (m, 9H); ${ }^{13} \mathrm{C} \mathrm{NMR}(62.9 \mathrm{MHz}$,
$\left.\mathrm{CDCl}_{3}\right): \delta=139.7,138.9,134.0,132.1,128.9,127.9,126.4,125.2,69.1$, $65.2,41.4,32.8,31.1,24.8,22.6$; elemental analysis calcd (\%) for $\mathrm{C}_{16} \mathrm{H}_{20} \mathrm{O}_{2}$ : C 78.65, $\mathrm{H}$ 8.25; found: C 78.58, H 8.25.

Methyl 4-(1-(4-methoxyphenylamino)butyl)benzoate (18a). A solution of $\mathrm{Me}_{3} \mathrm{SnLi}(0.83 \mathrm{mmol})$ in THF was treated with a solution of $\mathbf{1 7}^{[29]}(102$ $\mathrm{mg}, 0.38 \mathrm{mmol})$ in THF $(4 \mathrm{~mL})$ at $-78^{\circ} \mathrm{C}$. After stirring for $2 \mathrm{~h}, 1$ iodopropane ( $46 \mu \mathrm{L}, 0.47 \mathrm{mmol}$ ) was added and the resulting mixture was stirred for $2 \mathrm{~h}$ at $-78^{\circ} \mathrm{C}$. The reaction mixture was quenched with deoxygenated $\mathrm{pH} 7.0$ phosphate buffer, and then partitioned between $\mathrm{CH}_{2} \mathrm{Cl}_{2}$ and phosphate buffer. The aqueous phase was extracted with $\mathrm{CH}_{2} \mathrm{Cl}_{2}$, and the combined organic phase was washed with brine, dried, and concentrated. The residue was purified by column chromatography (neutral $\mathrm{Al}_{2} \mathrm{O}_{3}, \mathrm{CH}_{2} \mathrm{Cl}_{2} /$ hexane 2:1 to 3:1) to give 18a as a colorless oil (93 mg, $78 \%):{ }^{1} \mathrm{H}$ NMR $\left(250 \mathrm{MHz}, \mathrm{CD}_{2} \mathrm{Cl}_{2}\right): \delta=7.95(\mathrm{~d}, J=8.2 \mathrm{~Hz}, 2 \mathrm{H}), 7.42(\mathrm{~d}, J$ $=8.2 \mathrm{~Hz}, 2 \mathrm{H}), 6.64(\mathrm{~m}, 2 \mathrm{H}), 6.43(\mathrm{~m}, 2 \mathrm{H}), 4.31(\mathrm{t}, J=6.8 \mathrm{~Hz}, 1 \mathrm{H}), 3.93$ $(\mathrm{m}, 1 \mathrm{H}), 3.86(\mathrm{~s}, 3 \mathrm{H}), 3.64(\mathrm{~s}, 3 \mathrm{H}), 1.74(\mathrm{~m}, 2 \mathrm{H}), 1.37(\mathrm{~m}, 2 \mathrm{H}), 0.93(\mathrm{t}, J=$ $7.3 \mathrm{~Hz}, 3 \mathrm{H}) ;{ }^{13} \mathrm{C} \mathrm{NMR}\left(62.9 \mathrm{MHz}, \mathrm{CD}_{2} \mathrm{Cl}_{2}\right): \delta=167.3,152.5,151.0,142.0$, 130.2, 129.5, 127.1, 115.1, 114.8, 59.0, 56.1, 52.4, 41.4, 20.0, 14.3; IR (KBr): $v=1706 \mathrm{~cm}^{-1}$; elemental analysis calcd (\%) for $\mathrm{C}_{19} \mathrm{H}_{23} \mathrm{NO}_{3}: \mathrm{C}$ 72.82, H 7.40, N 4.47; found: C 72.56, H 7.60, N 4.61.

Methyl 4-[((4-methoxyphenyl)methylamino)methyl]benzoate (18b). A solution of $\mathrm{Me}_{3} \mathrm{SnLi}(0.80 \mathrm{mmol})$ in THF was treated with a solution of $\mathbf{1 7}^{[29]}$ (98 $\left.\mathrm{mg}, 0.36 \mathrm{mmol}\right)$ in $\mathrm{THF}(4 \mathrm{~mL})$ at $-78^{\circ} \mathrm{C}$. After stirring for $2 \mathrm{~h}$, $\mathrm{Me}_{2} \mathrm{SO}_{4}(45 \mu \mathrm{L}, 0.47 \mathrm{mmol})$ was added and the resulting mixture was stirred for $2 \mathrm{~h}$ at $-78{ }^{\circ} \mathrm{C}$, then slowly warmed to room temperature for $4 \mathrm{~h}$, and stirred 4 more $\mathrm{h}$ at this temperature. Work-up and purification as for 18a afforded $18 \mathrm{~b}$ as a yellowish oil that was recrystallized from $\mathrm{CH}_{2} \mathrm{Cl}_{2} /$ hexane to give a white solid $(63 \mathrm{mg}, 60 \%)$ : $\mathrm{mp} 57-58{ }^{\circ} \mathrm{C}$ $\left(\mathrm{CH}_{2} \mathrm{Cl}_{2} /\right.$ hexane); ${ }^{1} \mathrm{H} \mathrm{NMR}\left(250 \mathrm{MHz}, \mathrm{CD}_{2} \mathrm{Cl}_{2}\right): \delta=7.96$ (d, $J=8.0 \mathrm{~Hz}$, $2 \mathrm{H}), 7.33(\mathrm{~d}, J=8.0 \mathrm{~Hz}, 2 \mathrm{H}), 6.79(\mathrm{~d}, J=9.0 \mathrm{~Hz}, 2 \mathrm{H}), 6.70(\mathrm{~d}, J=9.0 \mathrm{~Hz}$, $2 \mathrm{H}), 4.48(\mathrm{~s}, 2 \mathrm{H}), 3.86(\mathrm{~s}, 3 \mathrm{H}), 3.72(\mathrm{~s}, 3 \mathrm{H}), 2.94(\mathrm{~s}, 3 \mathrm{H}) ;{ }^{13} \mathrm{C} \mathrm{NMR}(62.9$ $\left.\mathrm{MHz}, \mathrm{CD}_{2} \mathrm{Cl}_{2}\right): \delta=167.3,152.5,145.7,144.9,130.2,129.5,127.6,115.1$, $114.9,58.3,56.1,52.4,39.8$; IR (KBr): $v=1720 \mathrm{~cm}^{-1}$; elemental analysis calcd (\%) for $\mathrm{C}_{17} \mathrm{H}_{19} \mathrm{NO}_{3}$ : C 71.56, H 6.71, N 4.91; found: C 71.30, H 6.48, N 5.00 .

Methyl 4-(1-(4-methoxyphenyl)pyrrolidin-2-yl)benzoate (18c). A solution of $\mathrm{Me}_{3} \mathrm{SnLi}(0.77 \mathrm{mmol})$ in THF was treated with a solution of $\mathbf{1 7}^{[29]}$ (95 mg, $\left.0.35 \mathrm{mmol}\right)$ in THF $(4 \mathrm{~mL})$ at $-78^{\circ} \mathrm{C}$. After stirring for $2 \mathrm{~h}$, 1,3-dibromopropane ( $40 \mu \mathrm{L}, 0.39 \mathrm{mmol}$ ) was added and the resulting mixture was stirred for $1 \mathrm{~h}$ at $-78^{\circ} \mathrm{C}$, and then $4 \mathrm{~h}$ while warming to room temperature. Work-up as for $\mathbf{1 8 a}$, followed by column chromatography purification (neutral $\mathrm{Al}_{2} \mathrm{O}_{3}$, EtOAc/hexane 1:6), afforded $18 \mathbf{c}$ as a white solid (96 mg, 87\%): $\mathrm{mp} 79-80{ }^{\circ} \mathrm{C}\left(\mathrm{CH}_{2} \mathrm{Cl}_{2} /\right.$ hexane); ${ }^{1} \mathrm{H}$ NMR (250 MHz, $\left.\mathrm{CDCl}_{3}\right): \delta=7.96(\mathrm{~d}, J=8.3 \mathrm{~Hz}, 2 \mathrm{H}), 7.30(\mathrm{~d}, J=8.4 \mathrm{~Hz}, 2 \mathrm{H}), 6.74(\mathrm{~d}, J=$ $9.0 \mathrm{~Hz}, 2 \mathrm{H}), 6.39(\mathrm{~d}, J=9.0 \mathrm{~Hz}, 2 \mathrm{H}), 4.64(\mathrm{dd}, J=8.5,1.9 \mathrm{~Hz}, 1 \mathrm{H}), 3.88$ (s, 3H), $3.70(\mathrm{~m}, 1 \mathrm{H}), 3.69$ (s, 3H), 3.35 (dd, $J=16.1,8.3 \mathrm{~Hz}, 1 \mathrm{H}), 2.39$ (m, $1 \mathrm{H}), 1.93(\mathrm{~m}, 3 \mathrm{H}) ;{ }^{13} \mathrm{C} \mathrm{NMR}\left(62.9 \mathrm{MHz}, \mathrm{CDCl}_{3}\right): \delta=167.0,151.0,150.7$, $141.8,129.9,128.6,126.0,114.8,113.0,63.3,55.8,52.0,49.7,36.1,23.3$; IR (KBr): $v=1720,1713 \mathrm{~cm}^{-1}$; elemental analysis calcd (\%) for $\mathrm{C}_{19} \mathrm{H}_{21} \mathrm{NO}_{3}$ : C 73.29, $\mathrm{H}$ 6.80, N 4.50; found: C 72.99, H 7.09, N 4.46. Methyl 4-(1-(4-methoxyphenyl)piperidin-2-yl)benzoate (18d). Following the same procedure as for $\mathbf{1 8 c}$, but starting from $17^{[29]}(105 \mathrm{mg}, 0.39 \mathrm{mmol})$ and using 1.4-diiodobutane ( $62 \mu \mathrm{L}, 0.47 \mathrm{mmol})$ as the electrophile. The reaction mixture was stirred for $2 \mathrm{~h}$ at $-78^{\circ} \mathrm{C}$ and then 4 more $\mathrm{h}$ while warming to room temperature. Work-up and purification as for $\mathbf{1 8 a}$, gave 18d as a white solid (95 mg, 75\%): $\mathrm{mp} 83-84{ }^{\circ} \mathrm{C}\left(\mathrm{CH}_{2} \mathrm{Cl}_{2}\right.$-hexane); ${ }^{1} \mathrm{H}$ $\operatorname{NMR}\left(250 \mathrm{MHz}, \mathrm{CD}_{2} \mathrm{Cl}_{2}\right): \delta=7.81(\mathrm{~d}, J=8.3 \mathrm{~Hz}, 2 \mathrm{H}), 7.35(\mathrm{~d}, J=8.3 \mathrm{~Hz}$, $2 \mathrm{H}), 6.90(\mathrm{~m}, 2 \mathrm{H}), 6.64(\mathrm{~m}, 2 \mathrm{H}) 4.06(\mathrm{dd}, J=9.7,2.9 \mathrm{~Hz}, 1 \mathrm{H}), 3.81(\mathrm{~s}$, $3 \mathrm{H}), 3.64(\mathrm{~s}, 3 \mathrm{H}), 3.34(\mathrm{~m}, 1 \mathrm{H}), 2.80(\mathrm{~m}, 1 \mathrm{H}), 1.94-1.42(\mathrm{~m}, 6 \mathrm{H}) ;{ }^{13} \mathrm{C} \mathrm{NMR}$ $\left(62.9 \mathrm{MHz}, \mathrm{CD}_{2} \mathrm{Cl}_{2}\right): \delta=167.3,155.7,151.3,146.7,129.8,128.8,128.1$, 125.0, 114.2, 65.0, 57.9, 55.7, 52.3, 37.1, 27.1, 24.9; IR (KBr): $v=1721$ $\mathrm{cm}^{-1}$; elemental analysis calcd (\%) for $\mathrm{C}_{20} \mathrm{H}_{23} \mathrm{NO}_{3}$ : C 73.82, H 7.12, N 4.30; Found: C 73.42, H 7.46, N 4.27. 
Methyl 4-(1-(4-methoxyphenyl)-6-oxopiperidin-2-yl)benzoate (18e). Following the same procedure as for $\mathbf{1 8 c}$, but starting from $\mathbf{1 7}^{[29]}(100 \mathrm{mg}$, $0.37 \mathrm{mmol})$, using methyl 4-iodobutyrate $(102 \mathrm{mg}, 0.45 \mathrm{mmol})$ as the electrophile, and stirring for $2 \mathrm{~h}$ at $-78^{\circ} \mathrm{C}, 4 \mathrm{~h}$ while warming to room temperature, and then $14 \mathrm{~h}$ at $45^{\circ} \mathrm{C}$. Work-up and purification as for 18a, gave $\mathbf{1 8 d}$ as a white solid ( $84 \mathrm{mg}, 67 \%)$ : $\mathrm{mp} 82{ }^{\circ} \mathrm{C}\left(\mathrm{dec}\right.$.) $\left(\mathrm{CH}_{2} \mathrm{Cl}_{2}\right.$-hexane); ${ }^{1} \mathrm{H}$ NMR $\left(250 \mathrm{MHz}, \mathrm{CD}_{2} \mathrm{Cl}_{2}\right): \delta=7.94(\mathrm{~d}, J=8.1 \mathrm{~Hz}, 2 \mathrm{H}), 7.32(\mathrm{~d}, J=8.1$ $\mathrm{Hz}, 2 \mathrm{H}), 7.01(\mathrm{~d}, J=8.7 \mathrm{~Hz}, 2 \mathrm{H}), 6.74(\mathrm{~d}, J=8.7 \mathrm{~Hz}, 2 \mathrm{H}), 5.01(\mathrm{t}, J=5.1$ $\mathrm{Hz}, 1 \mathrm{H}), 3.86(\mathrm{~s}, 3 \mathrm{H}), 3.70(\mathrm{~s}, 3 \mathrm{H}), 2.63(\mathrm{~m}, 2 \mathrm{H}), 2.34(\mathrm{~m}, 1 \mathrm{H}), 1.90(\mathrm{~m}$. $3 \mathrm{H}) ;{ }^{13} \mathrm{C}$ NMR $\left(62.9 \mathrm{MHz}, \mathrm{CD}_{2} \mathrm{Cl}_{2}\right): \delta=171.1,167.0,158.5,147.5,135.5$, 130.1, 130.0, 129.1, 127.7, 114.4, 65.6, 55.8, 52.5, 33.2, 32.8, 18.4; IR (KBr): $v=1718,1707 \mathrm{~cm}^{-1}$. HRMS (ESI): $m / z$ calcd for $\mathrm{C}_{20} \mathrm{H}_{22} \mathrm{NO}_{4}$ : $340.1549\left[M+\mathrm{H}^{+}\right]$; found: 340.1543 .

\section{Procedure Using Substoichiometric Sn-reagent}

Small pieces of lithium wire $(56 \mathrm{mg}, 8 \mathrm{mmol})$ were suspended in dry THF $(1 \mathrm{~mL})$ at room temperature, and $\mathrm{Me}_{3} \mathrm{SnCl}(40 \mu \mathrm{L}, 0.04 \mathrm{mmol})$ was added. After being stirred for $30 \mathrm{~min}$, the suspension was cooled to $-78^{\circ} \mathrm{C}$ and treated with a solution of the corresponding diester $(0.4 \mathrm{mmol})$ in THF (1 $\mathrm{mL}$ ). After $16 \mathrm{~h}$ at $-78^{\circ} \mathrm{C}$, the solution was transferred $\mathrm{d}^{[30]}$ via cannula to a flask cooled to $-78{ }^{\circ} \mathrm{C}$, and then treated with the corresponding electrophile, the reaction mixture was stirred for $6 \mathrm{~h}$ while slowly warming to room temperature. Work-up as for 18a and column chromatography purification $\left(\mathrm{SiO}_{2}, \mathrm{EtOAc} /\right.$ hexane 1:20) afforded the corresponding bicycles $\mathbf{2 1 \mathbf { a } ^ { [ 1 0 ] }}(90$ $\mathrm{mg}, 77 \%$ yield), $\mathbf{2 1 \mathbf { b } ^ { [ 1 0 ] }}(83 \mathrm{mg}, 68 \%), \mathbf{2 2 a}^{[10]}\left(\mathrm{SiO}_{2}\right.$, EtOAc/hexane 1:10, $73 \mathrm{mg}, 60 \%$ ) and $\mathbf{1 0 b}$ (neutral $\mathrm{Al}_{2} \mathrm{O}_{3}, \mathrm{CH}_{2} \mathrm{Cl}_{2} /$ hexane 1:1, $64 \mathrm{mg}, 56 \%$ ). 5-Methyl 2-(1R,2S,5R)-5-methyl-2-(2-phenylpropan-2-yl)cyclohexyl pyridine-2,5-dicarboxylate (24e). A suspension of 2-carboxy-5methoxycarbonylpyridine ${ }^{[31]}(\mathbf{2 3}, 200 \mathrm{mg}, 1.10 \mathrm{mmol})$ in $\mathrm{CH}_{2} \mathrm{Cl}_{2}(6 \mathrm{~mL})$ was treated with (-)-8-phenylmenthol (256 mg, $1.10 \mathrm{~mol})$, DMAP (22 mg, $0.18 \mathrm{mmol}$ ) and EDC (238 mg, $1.24 \mathrm{mmol})$ at room temperature. The reaction mixture was refluxed in a sealed tube and, each $48 \mathrm{~h}$, more EDC (238 mg, $1.24 \mathrm{mmol}$ ) and DMAP (22 mg, $0.18 \mathrm{mmol})$ were added. After being refluxed for 7 days, the resulting solution was cooled to room temperature and washed with water and satd aqueous $\mathrm{NaCl}$. The organic phase was dried $\left(\mathrm{Na}_{2} \mathrm{SO}_{4}\right)$ and evaporated. Column chromatography of the residue $\left(\mathrm{SiO}_{2}, \mathrm{EtOAc} / \mathrm{Hexane} 1: 6\right)$ afforded $24 \mathrm{e}(354 \mathrm{mg}, 81 \%)$ as a white solid after recrystallization from MeOH: mp: $131-133{ }^{\circ} \mathrm{C} ;{ }^{1} \mathrm{H}$ NMR $(250$ $\left.\mathrm{MHz}, \mathrm{CDCl}_{3}\right): \delta=9.15(\mathrm{dd}, J=2.1,0.7 \mathrm{~Hz}, 1 \mathrm{H}), 8.14(\mathrm{dd}, J=8.1,2.1 \mathrm{~Hz}$, 1H), $7.22(\mathrm{~m}, 3 \mathrm{H}), 6.99$ (t, $J=7.7 \mathrm{~Hz}, 2 \mathrm{H}), 6.80$ (t, $J=7.3 \mathrm{~Hz}, 1 \mathrm{H}), 5.14$ (td, $J=10.8,4.5 \mathrm{~Hz}, 1 \mathrm{H}), 3.93$ (s, 3H), 2.24 (td, $J=12.1,3.6 \mathrm{~Hz}, 1 \mathrm{H}), 1.95$ $(\mathrm{m}, 1 \mathrm{H}), 1.83(\mathrm{~m}, 1 \mathrm{H}), 1.68(\mathrm{~m}, 1 \mathrm{H}), 1.51(\mathrm{~m}, 1 \mathrm{H}), 1.29(\mathrm{~s}, 3 \mathrm{H}), 1.17(\mathrm{~s}$, $3 \mathrm{H}), 1.15(\mathrm{~m}, 2 \mathrm{H}), 0.91(\mathrm{~m}, 1 \mathrm{H}), 0.85(\mathrm{~d}, J=6.5 \mathrm{~Hz}, 3 \mathrm{H}) ;{ }^{13} \mathrm{C}$ NMR $(62.9$ $\left.\mathrm{MHz}, \mathrm{CDCl}_{3}\right): \delta=164.9,162.9,151.5,150.7,150.3,137.6,127.8,127.7$, $125.1,124.7,124.3,75.9,52.6,50.2,41.4,39.4,34.4,31.2,29.2,26.3$, 23.5, 21.7; elemental analysis calcd (\%) for $\mathrm{C}_{24} \mathrm{H}_{29} \mathrm{NO}_{4}: \mathrm{C} 72.89, \mathrm{H} 7.39, \mathrm{~N}$ 3.54; found: C 72.76, H 7.47, N 3.64 .

(R)-6-Methyl 8a-[(1R,2S,5R)-5-methyl-2-(2-phenylpropan-2yl)cyclohexyl] 1,2,3,8a-tetrahydroindolizine-6,8a-dicarboxylate (25e). A solution of $\mathrm{Me}_{3} \mathrm{SnLi}(0.40 \mathrm{mmol})$ in THF was treated with a solution of $24 \mathrm{e}$ (70 mg, $0.18 \mathrm{mmol}$ ) in THF at $-78^{\circ} \mathrm{C}$. After stirring for $45 \mathrm{~min}, 1,3-$

dibromopropane ( $25 \mu \mathrm{L}, 0.25 \mathrm{mmol})$ was added. The reaction mixture was stirred for $12 \mathrm{~h}$ while slowly warming to room temperature. Work-up as for 15a, followed by column chromatography purification $\left(\mathrm{SiO}_{2}\right.$,

EtOAc/hexane 1:6), afforded 25e as a white solid (61 mg, 79\%) after crystallization from $\mathrm{Et}_{2} \mathrm{O} / \mathrm{CH}_{2} \mathrm{Cl}_{2}: \mathrm{mp} 130-133{ }^{\circ} \mathrm{C} ;{ }^{1} \mathrm{H} \mathrm{NMR}(750 \mathrm{MHz}$, $\left.\mathrm{CDCl}_{3}\right): \delta=7.48(\mathrm{~s}, 1 \mathrm{H}), 7.19(\mathrm{~m}, 4 \mathrm{H}), 7.08(\mathrm{~m}, 1 \mathrm{H}), 6.42(\mathrm{dd}, J=9.5,1.0$ $\mathrm{Hz}, 1 \mathrm{H}), 4.88(\mathrm{~d}, J=9.5 \mathrm{~Hz}, 1 \mathrm{H}), 4.66(\mathrm{td}, J=10.6,4.4 \mathrm{~Hz}, 1 \mathrm{H}), 3.65(\mathrm{~m}$, $1 \mathrm{H}), 3.62(\mathrm{~s}, 3 \mathrm{H}), 3.49(\mathrm{dt}, J=10.4,7.6 \mathrm{~Hz}, 1 \mathrm{H}), 2.32(\mathrm{~m}, 1 \mathrm{H}), 1.97(\mathrm{~m}$, $1 \mathrm{H}), 1.84$ (ddd, $J=12.3,10.6,3.5 \mathrm{~Hz}, 1 \mathrm{H}), 1.74(\mathrm{~m}, 3 \mathrm{H}), 1.44(\mathrm{~m}, 1 \mathrm{H})$, $1.31(\mathrm{~m}, 2 \mathrm{H}), 1.22(\mathrm{~s}, 3 \mathrm{H}), 1.17(\mathrm{~s}, 3 \mathrm{H}), 0.88(\mathrm{~m}, 2 \mathrm{H}), 0.77(\mathrm{~d}, J=6.5 \mathrm{~Hz}$, $3 \mathrm{H}), 0.68$ (ddd, $J=25.0,13.0,3.5 \mathrm{~Hz}, 1 \mathrm{H}) ;{ }^{13} \mathrm{C} \mathrm{NMR}\left(62.9 \mathrm{MHz}, \mathrm{CDCl}_{3}\right)$ : $\delta=171.9,166.8,150.1,143.3,127.9,125.8,125.3,123.3,109.3,98.8$, 76.3, 68.7, 51.1, 50.7, 50.2, 41.2, 40.2, 37.6, 34.4, 31.2, 30.1, 27.2, 24.4,
21.7, 20.9; IR (KBr): $v=1728,1692 \mathrm{~cm}^{-1}$; elemental analysis calcd (\%) for $\mathrm{C}_{27} \mathrm{H}_{35} \mathrm{NO}_{4}$ : C 74.11, H 8.06, N 3.20; found: C 74.16, H 8.19, N 3.17. (R)-7-Methyl 9a-[(1R,2S,5R)-5-methyl-2-(2-phenylpropan-2yl)cyclohexyl] 2,3,4,9a-tetrahydro- $1 \mathrm{H}$-quinolizine-7,9a-dicarboxylate (26e). 26e was prepared from $24 \mathrm{e}(56 \mathrm{mg}, 0.14 \mathrm{mmol})$ following the above procedure but using 1,4-dibromobutane $(44 \mu \mathrm{L}, 0.36 \mathrm{mmol})$ as the electrophile at $-78^{\circ} \mathrm{C}$ for $1 \mathrm{~h}$, then DMF $(1 \mathrm{~mL})$ was added and, after 20 $\mathrm{min}$, the cooling bath was removed and the reaction mixture was allowed to reach room temperature, and then heated at $60^{\circ} \mathrm{C}$ for $12 \mathrm{~h}$. Work-up as for 15a, followed by column chromatography purification $\left(\mathrm{SiO}_{2}\right.$,

EtOAc/hexane 1:6), afforded $26 \mathrm{e}$ as a pale yellow oil in $58 \%$ yield $(37 \mathrm{mg})$ : ${ }^{1} \mathrm{H}$ NMR $\left(750 \mathrm{MHz}, \mathrm{CDCl}_{3}\right): \delta=7.26(\mathrm{~m}, 5 \mathrm{H}), 7.14(\mathrm{~m}, 1 \mathrm{H}), 6.28(\mathrm{dd}, J=$ 9.8, $1.3 \mathrm{~Hz}, 1 \mathrm{H}), 4.81(\mathrm{td}, J=10.6,4.3 \mathrm{~Hz}, 1 \mathrm{H}), 4.50(\mathrm{~d}, J=9.8 \mathrm{~Hz}, 1 \mathrm{H})$, $3.64(\mathrm{~s}, 3 \mathrm{H}), 3.57(\mathrm{td}, J=13.1,3.3 \mathrm{~Hz}, 1 \mathrm{H}), 3.18(\mathrm{~m}, 1 \mathrm{H}), 2.08(\mathrm{~m}, 1 \mathrm{H})$, $1.97(\mathrm{~m}, 2 \mathrm{H}), 1.72(\mathrm{~m}, 2 \mathrm{H}), 1.62(\mathrm{~m}, 1 \mathrm{H}), 1.54(\mathrm{~m}, 2 \mathrm{H}), 1.41(\mathrm{~m}, 2 \mathrm{H}), 1.30$ $(\mathrm{m}, 1 \mathrm{H}), 1.29(\mathrm{~s}, 3 \mathrm{H}), 1.20(\mathrm{~s}, 3 \mathrm{H}), 0.97(\mathrm{~m}, 2 \mathrm{H}), 0.84(\mathrm{~d}, J=6.6 \mathrm{~Hz}, 3 \mathrm{H})$, $0.77(\mathrm{ddd}, J=25.0,13.0,3.5 \mathrm{~Hz}, 1 \mathrm{H}) ;{ }^{13} \mathrm{C} \mathrm{NMR}\left(62.9 \mathrm{MHz}, \mathrm{CDCl}_{3}\right): \delta=$ $170.1,166.6,150.5,148.3,128.0,125.6,125.3,122.5,113.5,95.7,76.8$, 65.6, 52.4, 50.6, 49.8, 41.6, 40.1, 35.6, 34.4, 31.3, 29.0, 27.2, 25.5, 25.1, 21.8, 21.3; IR (KBr): $v=1726,1689 \mathrm{~cm}^{-1}$; elemental analysis calcd (\%) for $\mathrm{C}_{28} \mathrm{H}_{37} \mathrm{NO}_{4}$ : C 74.47, $\mathrm{H} 8.26, \mathrm{~N} 3.10$; found: C 74.62, H 8.46, N 3.15. (R)-3-Methyl 10a-[(1R,2S,5R)-5-methyl-2-(2-phenylpropan-2yl)cyclohexyl] 6,7,8,9,10,10a-hexahydropyrido[1,2-a] azepine-3,10adicarboxylate (27e). 27e was prepared from $24 \mathrm{e}(50 \mathrm{mg}, 0.13 \mathrm{mmol})$ following the above procedure but using 1,5-diiodopentane ( $25 \mu \mathrm{L}, 0.17$ mmol) as the electrophile at $-78{ }^{\circ} \mathrm{C}$ for $1 \mathrm{~h}$, then DMF $(1 \mathrm{~mL})$ was added and, after $20 \mathrm{~min}$, the cooling bath was removed and the reaction mixture was allowed to reach room temperature, and then heated at $60^{\circ} \mathrm{C}$ for $12 \mathrm{~h}$. Work-up as for 15a, followed by column chromatography purification $\left(\mathrm{SiO}_{2}, \mathrm{EtOAc} /\right.$ hexane 1:6) afforded $27 \mathrm{e}$ as a pale yellow oil in $62 \%$ yield (37 mg): ${ }^{1} \mathrm{H}$ NMR $\left(250 \mathrm{MHz}, \mathrm{CDCl}_{3}\right): \delta=7.38(\mathrm{~s}, 1 \mathrm{H}), 7.26(\mathrm{~m}, 4 \mathrm{H}), 7.14$ (m, 1H), 6.47 (dd, $J=9.6,1.2 \mathrm{~Hz}, 1 \mathrm{H}), 4.76(\mathrm{td}, J=10.6,4.4 \mathrm{~Hz}, 1 \mathrm{H}), 4.59$ $(\mathrm{d}, J=9.6 \mathrm{~Hz}, 1 \mathrm{H}), 3.66(\mathrm{~s}, 3 \mathrm{H}), 3.29(\mathrm{~m}, 2 \mathrm{H}), 2.12-1.14(\mathrm{~m}, 19 \mathrm{H}), 0.96$ $(\mathrm{m}, 2 \mathrm{H}), 0.82(\mathrm{~d}, J=6.4 \mathrm{~Hz}, 3 \mathrm{H}), 0.75(\mathrm{~m}, 1 \mathrm{H}) ;{ }^{13} \mathrm{C} \mathrm{NMR}(62.9 \mathrm{MHz}$, $\mathrm{CDCl}_{3}$, main isomer): $\delta=172.7,166.6,150.4,147.3,128.0,125.7,125.3$, 124.5, 113.5, 97.4, 76.4, 67.7, 53.3, 50.6, 50.1, 41.6, 40.4, 40.2, 34.4, 31.3, $31.2,29.5,29.0,27.2,25.0,22.4,21.7$; IR (KBr): $v=1729,1690 \mathrm{~cm}^{-1}$; elemental analysis calcd (\%) for $\mathrm{C}_{29} \mathrm{H}_{39} \mathrm{NO}_{4}$ : C 74.81, H 8.44, N 3.01; found: C 75.15, H 8.34, N 3.12.

6-(Methoxycarbonyl)quinoline-2-carboxylic acid. To a stirred solution of dimethyl quinoline-2,6-dicarboxylate ${ }^{[32]}(1.75 \mathrm{~g}, 7.1 \mathrm{mmol})$ in $45 \mathrm{~mL}$ of dioxane at room temperature was added a solution of $\mathrm{LiOH} \cdot \mathrm{H}_{2} \mathrm{O}(300 \mathrm{mg}$, $7.1 \mathrm{mmol})$ in $\mathrm{H}_{2} \mathrm{O}(5.6 \mathrm{~mL})$. After stirring for $16 \mathrm{~h}$ the reaction mixture was filtered, and the filtrate was washed with dioxane. The solid was dissolved in water, and the aqueous solution was cooled to $0{ }^{\circ} \mathrm{C}$ and acidified with $\mathrm{HCl}$. The precipitate was isolated by filtration and washed once with water giving $1.40 \mathrm{~g}$ of the product as a white powder after drying (85\%): ${ }^{1} \mathrm{H}$ NMR $\left(250 \mathrm{MHz}, \mathrm{CD}_{3} \mathrm{OD}\right): \delta=8.74(\mathrm{~s}, 1 \mathrm{H}), 8.65(\mathrm{~d}, J=8.5 \mathrm{~Hz}, 1 \mathrm{H}), 8.41-8.22$ (m, 3H), 4.00 (s, 3H); ${ }^{13} \mathrm{C}$ NMR (62.9 MHz, DMSO-D $): ~ \delta=166.0,165.7$, $150.7,148.3,139.5,130.8,130.2,129.3,129.0,128.1,121.6,52.7$; IR $(\mathrm{KBr}): v=1724 \mathrm{~cm}^{-1}$; elemental analysis calcd $(\%)$ for $\mathrm{C}_{12} \mathrm{H}_{9} \mathrm{NO}_{4}$ : C 62.34, H 3.92, N 6.06; found: C 62.62, H 3.98, N 6.31.

\section{6-Methyl 2-[(1R,2S,5R)-5-methyl-2-(2-phenylpropan-2-yl)cyclohexyl]} quinoline-2,6-dicarboxylate (28). A suspension of 6-

(methoxycarbonyl)quinoline-2-carboxylic acid $(700 \mathrm{mg}, 3.0 \mathrm{mmol})$ in $\mathrm{CH}_{2} \mathrm{Cl}_{2}(20 \mathrm{~mL})$ was treated with (-)-8-phenylmenthol (705 mg, $\left.3.0 \mathrm{~mol}\right)$, DMAP (135 mg, $1.1 \mathrm{mmol})$ and di(2-pyridyl) carbonate (DPC) $(820 \mathrm{mg}$, $3.8 \mathrm{mmol})$ at room temperature. The reaction mixture was refluxed in a sealed tube and, after $24 \mathrm{~h}$, more DPC (650 mg, $3.0 \mathrm{mmol}$ ) and DMAP (135 $\mathrm{mg}, 1.1 \mathrm{mmol}$ ) were added. After being refluxed for 4 days, the resulting solution was cooled to room temperature, $\mathrm{pH} 7.0$ phosphate buffer was added and the mixture was extracted twice with $\mathrm{CH}_{2} \mathrm{Cl}_{2}$. The organic phase was dried $\left(\mathrm{Na}_{2} \mathrm{SO}_{4}\right)$ and evaporated. Flash column chromatography of the 
residue $\left(\mathrm{SiO}_{2}, \mathrm{EtOAc} /\right.$ Hexane 1:10) afforded $\mathbf{2 8}(1.16 \mathrm{~g}, 85 \%)$ as a white foam: ${ }^{1} \mathrm{H}$ NMR $\left(250 \mathrm{MHz}, \mathrm{CD}_{2} \mathrm{Cl}_{2}\right): \delta=8.61(\mathrm{~d}, J=2.0 \mathrm{~Hz}, 1 \mathrm{H}), 8.25(\mathrm{~m}$, $3 \mathrm{H}), 7.43(\mathrm{~d}, J=8.5 \mathrm{~Hz}, 1 \mathrm{H}), 7.26(\mathrm{~d}, J=7.6 \mathrm{~Hz}, 2 \mathrm{H}), 7.02(\mathrm{t}, J=7.5 \mathrm{~Hz}$, $2 \mathrm{H}), 6.79(\mathrm{t}, J=7.3 \mathrm{~Hz}, 1 \mathrm{H}), 5.15(\mathrm{td}, J=10.7,4.4 \mathrm{~Hz}, 1 \mathrm{H}), 3.98(\mathrm{~s}, 3 \mathrm{H})$, 2.29 (ddd, $J=12.1,10.4,3.6 \mathrm{~Hz}, 1 \mathrm{H}), 2.05(\mathrm{~m}, 1 \mathrm{H}), 1.90-1.49(\mathrm{~m}, 3 \mathrm{H})$, $1.38(\mathrm{~s}, 3 \mathrm{H}), 1.26(\mathrm{~s}, 3 \mathrm{H}), 1.23(\mathrm{~m}, 2 \mathrm{H}), 0.98(\mathrm{~m}, 1 \mathrm{H}), 0.92(\mathrm{~d}, J=6.4 \mathrm{~Hz}$, $3 \mathrm{H}) ;{ }^{13} \mathrm{C}$ NMR $\left(62.9 \mathrm{MHz}, \mathrm{CDCl}_{3}\right): \delta=166.1,163.3,151.5,149.7,149.0$, 137.9, 131.0, 130.3, 129.4, 129.1, 128.0, 127.8, 125.1, 124.7, 121.6, 76.1, 52.4, 50.3, 41.4, 39.5, 34.4, 31.2, 28.7, 26.4, 24.1, 21.7; IR (KBr): $v=1726$ $\mathrm{cm}^{-1}$; HRMS (ESI): $m / z$ calcd for $\mathrm{C}_{28} \mathrm{H}_{31} \mathrm{NO}_{4}+\mathrm{Na}^{+}: 468.2145\left[M+\mathrm{Na}^{+}\right]$; found: 468.2149; elemental analysis calcd (\%) for $\mathrm{C}_{28} \mathrm{H}_{31} \mathrm{NO}_{4}$ : C 75.48, $\mathrm{H}$ 7.01, N 3.14; found: C 75.08, H 6.90, N 3.03.

(R)-6-Methyl 2-[(1R,2S,5R)-5-methyl-2-(2-phenylpropan-2yl)cyclohexyl] 2-propyl-1,2-dihydroquinoline-2,6-dicarboxylate (29a) A $-78^{\circ} \mathrm{C}$ solution of $\mathrm{Me}_{3} \mathrm{SnLi}(0.62 \mathrm{mmol})$ in THF $(0.7 \mathrm{~mL})$ was treated with a solution of $\mathbf{2 8}(127 \mathrm{mg}, 0.28 \mathrm{mmol})$ in THF (2.1 mL). After 1h, 1iodopropane $(50 \mu \mathrm{L}, 0.44 \mathrm{mmol})$ was added. The reaction mixture was stirred for $8 \mathrm{~h}$ while slowly warming to room temperature. Work-up as for 15a followed by column chromatography $\left(\mathrm{SiO}_{2}\right.$, EtOAc/Hexane 1:10) afforded 29a (125 mg, 90\%) as a white foam: ${ }^{1} \mathrm{H}$ NMR (500 MHz, $\left.\mathrm{CDCl}_{3}\right)$ : $\delta=7.66(\mathrm{dd}, J=8.4,2.0 \mathrm{~Hz}, 1 \mathrm{H}), 7.49(\mathrm{~d}, J=2.0 \mathrm{~Hz}, 1 \mathrm{H}), 7.34(\mathrm{~d}, J=4.2$ $\mathrm{Hz}, 4 \mathrm{H}), 7.23(\mathrm{~m}, 1 \mathrm{H}), 6.32(\mathrm{~d}, J=9.8 \mathrm{~Hz}, 1 \mathrm{H}), 6.31(\mathrm{~d}, J=8.3 \mathrm{~Hz}, 1 \mathrm{H})$, $5.36(\mathrm{dd}, J=9.8,2.1 \mathrm{~Hz}, 1 \mathrm{H}), 4.79(\mathrm{td}, J=10.7,4.3 \mathrm{~Hz}, 1 \mathrm{H}), 3.82(\mathrm{~s}, 3 \mathrm{H})$, 3.77 (s, $1 \mathrm{H}), 2.12$ (ddd, $J=12.1,10.5,3.6 \mathrm{~Hz}, 1 \mathrm{H}), 1.77(\mathrm{~m}, 2 \mathrm{H}), 1.66(\mathrm{~m}$, $2 \mathrm{H}), 1.41(\mathrm{~m}, 2 \mathrm{H}), 1.29(\mathrm{~m}, 5 \mathrm{H}), 1.17(\mathrm{~s}, 3 \mathrm{H}), 1.14(\mathrm{~m}, 1 \mathrm{H}), 0.91(\mathrm{t}, J=7.2$ $\mathrm{Hz}, 3 \mathrm{H}), 0.87(\mathrm{~m}, 2 \mathrm{H}), 0.84(\mathrm{~d}, J=6.4 \mathrm{~Hz}, 3 \mathrm{H}) ;{ }^{13} \mathrm{C} \mathrm{NMR}(62.9 \mathrm{MHz}$, $\left.\mathrm{CDCl}_{3}\right): \delta=172.9,167.1,152.1,146.9,131.1,128.6,128.3,126.0,125.6$, 125.2, 123.1, 118.2, 117.4, 111.7, 76.4, 63.1, 51.5, 49.6, 43.2, 41.1, 39.6, 34.4, 31.2, 28.9, 26.6, 24.7, 21.7, 16.9, 14.1; IR (KBr): $v=1712 \mathrm{~cm}^{-1}$; HRMS (ESI): $m / z$ calcd for $\mathrm{C}_{31} \mathrm{H}_{39} \mathrm{NO}_{4}+\mathrm{Na}^{+}: 512.2771\left[M+\mathrm{Na}^{+}\right]$; found: 512.2775; elemental analysis calcd (\%) for $\mathrm{C}_{31} \mathrm{H}_{39} \mathrm{NO}_{4}$ : $\mathrm{C} 76.04, \mathrm{H} 8.03, \mathrm{~N}$ 2.86; found: C 76.30, H 8.27, N 2.74 .

(R)-6-Methyl 2-[(1R,2S,5R)-5-methyl-2-(2-phenylpropan-2yl)cyclohexyl] 2-(3,4-dimethylpent-3-en-1-yl)-1,2-dihydroquinoline-2,6dicarboxylate (29b). A $-78^{\circ} \mathrm{C}$ solution of $\mathrm{Me}_{3} \mathrm{SnLi}(0.42 \mathrm{mmol})$ in THF $(0.5 \mathrm{~mL})$ was treated with a solution of $\mathbf{2 8}(85 \mathrm{mg}, 0.19 \mathrm{mmol})$ in THF (1.4 $\mathrm{mL})$. After 1h, 5-bromo-2,3-dimethylpent-2-ene ${ }^{[33]}(65 \mathrm{mg}, 0.37 \mathrm{mmol})$ was added. The reaction mixture was stirred for $3 \mathrm{~h}$ while slowly warming to room temperature, and then stirred at $25^{\circ} \mathrm{C}$ for $12 \mathrm{~h}$. Work-up as for 15a, followed by column chromatography purification $\left(\mathrm{SiO}_{2}, \mathrm{EtOAc} /\right.$ hexane 1:10), afforded $29 \mathrm{~b}$ as a pale yellow oil in $77 \%$ yield $(80 \mathrm{mg}):{ }^{1} \mathrm{H}$ NMR $\left(500 \mathrm{MHz}, \mathrm{CD}_{2} \mathrm{Cl}_{2}\right): \delta=7.64(\mathrm{dd}, J=8.4,2.0 \mathrm{~Hz}, 1 \mathrm{H}), 7.49(\mathrm{~d}, J=2.0 \mathrm{~Hz}$, $1 \mathrm{H}), 7.34(\mathrm{~m}, 4 \mathrm{H}), 7.23(\mathrm{~m}, 1 \mathrm{H}), 6.38(\mathrm{~d}, J=8.3 \mathrm{~Hz}, 1 \mathrm{H}), 6.37(\mathrm{~d}, J=9.8$ $\mathrm{Hz}, 1 \mathrm{H}), 5.38$ (dd, $J=9.9,2.0 \mathrm{~Hz}, 1 \mathrm{H}), 4.79$ (td, $J=10.7,4.3 \mathrm{~Hz}, 1 \mathrm{H}), 3.97$ (s, 1H), 3.79 (s, 3H), 2.12 (ddd, $J=12.4,10.7,3.5 \mathrm{~Hz}, 1 \mathrm{H}), 2.05$ (td, $J=$ $12.6,4.8 \mathrm{~Hz}, 1 \mathrm{H}), 1.97$ (td, $J=12.7,4.8 \mathrm{~Hz}, 1 \mathrm{H}), 1.83-1.69$ (m, $3 \mathrm{H}), 1.63$ (m, 10H), $1.48(\mathrm{~m}, 2 \mathrm{H}), 1.28(\mathrm{~s}, 3 \mathrm{H}), 1.18(\mathrm{~s}, 3 \mathrm{H}), 1.13(\mathrm{~m}, 1 \mathrm{H}), 0.90-0.81$ (m, 5H); ${ }^{13} \mathrm{C} \mathrm{NMR}\left(62.9 \mathrm{MHz}, \mathrm{CDCl}_{3}\right): \delta=172.7,167.1,152.2,147.0$, 131.2, 128.7, 128.3, 126.3, 125.6, 125.2, 124.8, 123.1, 118.3, 117.5, 111.8, 63.2, 51.5, 49.7, 41.2, 39.6, 39.1, 34.4, 31.3, 29.0, 28.6, 26.6, 24.6, 21.7, 20.6, 20.1, 18.5; IR (KBr): $v=1713 \mathrm{~cm}^{-1}$; HRMS (ESI): $m / z$ calcd for $\mathrm{C}_{35} \mathrm{H}_{46} \mathrm{NO}_{4}$ : $544.3421\left[M+\mathrm{H}^{+}\right]$; found: 544.3404; elemental analysis calcd (\%) for $\mathrm{C}_{35} \mathrm{H}_{45} \mathrm{NO}_{4}$ : C 77.31, H 8.34, N 2.58; found: C 77.06, H 8.62, N 2.44 .

\section{(R)-6-Methyl 2-[(1R,2S,5R)-5-methyl-2-(2-phenylpropan-2-} yl)cyclohexyl] 2-phenethyl-1,2-dihydroquinoline-2,6-dicarboxylate (29c). A $-78^{\circ} \mathrm{C}$ solution of $\mathrm{Me}_{3} \mathrm{SnLi}(0.88 \mathrm{mmol})$ in $\mathrm{THF}(1 \mathrm{~mL})$ was treated with a solution of $\mathbf{2 8}(180 \mathrm{mg}, 0.4 \mathrm{mmol})$ in THF $(3 \mathrm{~mL})$. After $1 \mathrm{~h}$, 2-(bromoethyl)benzene ( $60 \mu \mathrm{L}, 0.44 \mathrm{mmol})$ was added. The reaction mixture was stirred for $3 \mathrm{~h}$ while slowly warming to room temperature, and then stirred at $25^{\circ} \mathrm{C}$ for $12 \mathrm{~h}$. Work-up as for $\mathbf{1 5 a}$, followed by column chromatography purification $\left(\mathrm{SiO}_{2}\right.$, EtOAc/hexane 1:10), afforded $29 \mathrm{c}$ as a white foam in $70 \%$ yield $(154 \mathrm{mg}, 260 \mathrm{mg})$ : ${ }^{1} \mathrm{H} \mathrm{NMR}\left(750 \mathrm{MHz}, \mathrm{CD}_{2} \mathrm{Cl}_{2}\right)$ : $\delta=7.68(\mathrm{dd}, J=8.4,2.0 \mathrm{~Hz}, 1 \mathrm{H}), 7.53(\mathrm{~d}, J=1.9 \mathrm{~Hz}, 1 \mathrm{H}), 7.38-7.15(\mathrm{~m}$, $10 \mathrm{H}), 6.43(\mathrm{~d}, J=9.9 \mathrm{~Hz}, 1 \mathrm{H}), 6.40(\mathrm{~d}, J=8.4 \mathrm{~Hz}, 1 \mathrm{H}), 5.44(\mathrm{dd}, J=9.9$, $2.0 \mathrm{~Hz}, 1 \mathrm{H}), 4.81(\mathrm{dt}, J=10.7,4.3 \mathrm{~Hz}, 1 \mathrm{H}), 3.95(\mathrm{~s}, 1 \mathrm{H}), 3.81(\mathrm{~s}, 3 \mathrm{H}), 2.62$ (m, 2H), $2.16(\mathrm{ddd}, J=12.2,10.5,3.6 \mathrm{~Hz}, 1 \mathrm{H}), 2.02(\mathrm{ddd}, J=13.6,12.1$, $5.1 \mathrm{~Hz}, 1 \mathrm{H}), 1.83-1.72(\mathrm{~m}, 3 \mathrm{H}), 1.66(\mathrm{~m}, 1 \mathrm{H}), 1.46(\mathrm{~m}, 1 \mathrm{H}), 1.28(\mathrm{~s}, 3 \mathrm{H})$, $1.18(\mathrm{~s}, 3 \mathrm{H}), 1.15(\mathrm{~m}, 1 \mathrm{H}), 0.89(\mathrm{~m}, 2 \mathrm{H}), 0.85(\mathrm{~d}, J=6.6 \mathrm{~Hz}, 3 \mathrm{H}) ;{ }^{13} \mathrm{C}$ NMR (62.9 MHz, $\left.\mathrm{CDCl}_{3}\right): \delta=172.6,167.1,152.3,146.8,141.4,131.2$, $128.7,128.42,128.36,128.32,126.6,125.9,125.5,125.2,122.7,118.4$, 117.3, 111.8, 76.5, 63.1, 51.5, 49.6, 42.6, 41.1, 39.5, 34.4, 31.2, 30.2, 29.3, 26.5, 24.2, 21.7; ; IR (KBr): $v=1712 \mathrm{~cm}^{-1}$; HRMS (ESI): $m / z$ calcd for $\mathrm{C}_{36} \mathrm{H}_{41} \mathrm{NO}_{4}+\mathrm{Na}^{+}: 574.2928\left[M+\mathrm{Na}^{+}\right]$; found: 574.2930; elemental analysis calcd (\%) for $\mathrm{C}_{36} \mathrm{H}_{41} \mathrm{NO}_{4} \mathrm{H}_{2} \mathrm{O}$ : C 75.89, H 7.61, N 2.46; found: C 75.78, $\mathrm{H}$ 7.21, N 2.37. (R)-6-Methyl 2-[(1R,2S,5R)-5-methyl-2-(2-phenylpropan2-yl)cyclohexyl] 2-(2-(2-methyl-1,3-dioxolan-2-yl)ethyl)-1,2dihydroquinoline-2,6-dicarboxylate (29d). A $-78^{\circ} \mathrm{C}$ solution of $\mathrm{Me}_{3} \mathrm{SnLi}$ $(0.42 \mathrm{mmol})$ in THF $(0.5 \mathrm{~mL})$ was treated with a solution of $\mathbf{2 8}(85 \mathrm{mg}$, $0.19 \mathrm{mmol})$ in THF (1.2 mL). After 1h, 2-(2-bromoethyl)-2-methyl-1,3dioxolane $^{[34]}(71 \mathrm{mg}, 0.36 \mathrm{mmol})$ was added, immediately followed by HMPA $(0.2 \mathrm{~mL})$. The reaction mixture was stirred for $24 \mathrm{~h}$ at $-78^{\circ} \mathrm{C}$. Work-up as for 15a, followed by column chromatography purification $\left(\mathrm{SiO}_{2}\right.$, EtOAc/hexane 1:3), afforded 29d as a white foam $(51 \mathrm{mg}, 48 \%):{ }^{1} \mathrm{H}$ $\operatorname{NMR}\left(750 \mathrm{MHz}, \mathrm{CDCl}_{3}\right): \delta=7.65(\mathrm{dd}, J=8.5,2.0 \mathrm{~Hz}, 1 \mathrm{H}), 7.48(\mathrm{~d}, J=$ $2.0 \mathrm{~Hz}, 1 \mathrm{H}), 7.39-7.31(\mathrm{~m}, 4 \mathrm{H}), 7.24(\mathrm{~m}, 1 \mathrm{H}), 6.33$ (d, $J=9.9 \mathrm{~Hz}, 1 \mathrm{H}), 6.28$ (d, $J=8.4 \mathrm{~Hz}, 1 \mathrm{H}), 5.34$ (dd, $J=9.9,2.0 \mathrm{~Hz}, 1 \mathrm{H}), 4.79$ (td, $J=10.7,4.3 \mathrm{~Hz}$, $1 \mathrm{H}), 3.99-3.89(\mathrm{~m}, 4 \mathrm{H}), 3.82(\mathrm{~s}, 3 \mathrm{H}), 3.64(\mathrm{~s}, 1 \mathrm{H}), 2.11$ (ddd, $J=12.3,10.5$, $3.5 \mathrm{~Hz}, 1 \mathrm{H}), 1.85-1.73(\mathrm{~m}, 3 \mathrm{H}), 1.65(\mathrm{~m}, 3 \mathrm{H}), 1.59(\mathrm{~m}, 1 \mathrm{H}), 1.45(\mathrm{~m}, 1 \mathrm{H})$, $1.31(\mathrm{~s}, 3 \mathrm{H}), 1.27(\mathrm{~s}, 3 \mathrm{H}), 1.17(\mathrm{~s}, 3 \mathrm{H}), 1.12(\mathrm{~m}, 1 \mathrm{H}), 0.84(\mathrm{~m}, 2 \mathrm{H}), 0,83(\mathrm{~d}$, $J=6.4 \mathrm{~Hz}, 3 \mathrm{H}) ;{ }^{13} \mathrm{C} \mathrm{NMR}\left(62.9 \mathrm{MHz}, \mathrm{CDCl}_{3}\right): \delta=172.8,167.1,152.3$, 146.9, 131.2, 128.7, 128.4, 126.6, 125.6, 125.2, 122.8, 118.3, 117.2, 111.8, 109.7, 64.7, 62.7, 51.5, 49.8, 41.1, 39.6, 35.0, 34.4, 33.3, 31.2, 29.1, 26.6, 24.4, 24.1, 21.7; IR (KBr): $v=1712 \mathrm{~cm}^{-1}$; HRMS (ESI): $\mathrm{m} / z$ calcd for $\mathrm{C}_{34} \mathrm{H}_{43} \mathrm{NO}_{6}+\mathrm{Na}^{+}: 584.2983\left[M+\mathrm{Na}^{+}\right]$; found: 584.2981.

3-(Methoxycarbonyl)-7-methoxybenzofuran-2-carboxylic acid (31). A 0 ${ }^{\circ} \mathrm{C}$ solution of dimethyl 7-methoxybenzofuran-2,3-dicarboxylate ${ }^{[27]}(\mathbf{3 0}$, $6.07 \mathrm{~g}, 23 \mathrm{mmol})$ in a $1: 1$ dioxane $/ \mathrm{H}_{2} \mathrm{O}$ solution $(230 \mathrm{~mL})$ was treated with $\mathrm{LiOH} \cdot \mathrm{H}_{2} \mathrm{O}(1 \mathrm{~g}, 24 \mathrm{mmol})$ and the mixture was stirred for $2 \mathrm{~h}$. The solution was acidified with $6 \mathrm{~N} \mathrm{HCl}$, and the white solid obtained was collected, dried and used without further purification $(5.64 \mathrm{~g}, 98 \%): \mathrm{mp} 212-214{ }^{\circ} \mathrm{C}$ (MeOH); ${ }^{1} \mathrm{H}$ NMR (250 MHz, $\mathrm{CDCl}_{3}$ ): $\delta=14.18$ (br s, $\left.1 \mathrm{H}\right), 7.57$ (d, $J=8.1$ $\mathrm{Hz}, 1 \mathrm{H}), 7.34$ (t, $J=8.0 \mathrm{~Hz}, 1 \mathrm{H}), 6.98(\mathrm{~d}, J=7.9 \mathrm{~Hz}, 1 \mathrm{H}), 4.17$ (s, 3H), 4.00 (s, $3 \mathrm{H}) ;{ }^{13} \mathrm{C}$ NMR (62.9 MHz, DMSO): $\delta=162.8,159.2,146.4,145.3$, 142.9, 126.3, 125.8, 117.1, 113.6, 109.7, 56.0, 52.7; IR (KBr): $v=1760 \mathrm{~cm}$ ${ }^{1}$; HRMS (ESI): $m / z$ calcd for $\mathrm{C}_{12} \mathrm{H}_{11} \mathrm{O}_{6}: 251.0550\left[M+\mathrm{H}^{+}\right]$; found: 251.0551; elemental analysis calcd (\%) for $\mathrm{C}_{12} \mathrm{H}_{10} \mathrm{O}_{6}: \mathrm{C} 57.60, \mathrm{H}$ 4.03; found: C $57.25, \mathrm{H} 3.99$.

3-Methyl 2-[(1R,2S,5R)-5-methyl-2-(2-phenylpropan-2-yl)cyclohexyl] 7methoxybenzofuran-2,3-dicarboxylate (32). A solution of $\mathbf{3 1}(0,94 \mathrm{~g}$, $3.76 \mathrm{mmol}$ ), (-)-8-phenylmenthol (872 mg, $3.76 \mathrm{mmol}$ ), di-2-pyridyl carbonate (DPC) (850 mg, $3.94 \mathrm{mmol})$ and DMAP ( $83 \mathrm{mg}, 0.68 \mathrm{mmol})$ in dry dichloroethane $(18 \mathrm{~mL})$ was prepared in a sealed vessel, and refluxed for 1 day. The reaction mixture was cooled to room temperature, $\mathrm{H}_{2} \mathrm{O}$ was added to the mixture and the layers were separated. The organic layer was washed with water and brine, dried, and evaporated under reduced pressure. The crude product was purified by flash column chromatography (EtOAc/toluene 1:50) to give $32(1.47 \mathrm{~g}, 84 \%)$ as a white foam: $[\alpha]^{24}{ }_{\mathrm{D}}-$ 21.6 ( c 0.5, MeOH); ${ }^{1} \mathrm{H}$ NMR (250 MHz, $\mathrm{CD}_{2} \mathrm{Cl}_{2}$ ): $\delta=7.43$ (dd, $J=8.0$, $0.9 \mathrm{~Hz}, 1 \mathrm{H}), 7.30(\mathrm{t}, J=8.0 \mathrm{~Hz}, 1 \mathrm{H}), 7.23(\mathrm{~m}, 2 \mathrm{H}), 6.99(\mathrm{~m}, 3 \mathrm{H}), 6.66(\mathrm{~m}$, $1 \mathrm{H}), 5.12(\mathrm{td}, J=10.8,4.5 \mathrm{~Hz}, 1 \mathrm{H}), 4.03(\mathrm{~s}, 3 \mathrm{H}), 3.95(\mathrm{~s}, 3 \mathrm{H}), 2.10(\mathrm{~m}, 2 \mathrm{H})$, 1.82-1.43 (m, 3H), $1.34(\mathrm{~s}, 3 \mathrm{H}), 1.26(\mathrm{~s}, 3 \mathrm{H}), 1.20(\mathrm{~m}, 2 \mathrm{H}), 0.94(\mathrm{~m}, 1 \mathrm{H})$, $0.93(\mathrm{~d}, J=6.4 \mathrm{~Hz}, 3 \mathrm{H}) ;{ }^{13} \mathrm{C}$ NMR $\left(250 \mathrm{MHz}, \mathrm{CD}_{2} \mathrm{Cl}_{2}\right): \delta=163.2,158.0$, 151.4, 146.6, 146.2, 144.0, 128.1, 127.7, 125.7, 125.1, 118.0, 114.6, 109.4, 76.6, 56.6, 52.6, 51.3, 42.0, 40.2, 35.0, 32.0, 28.1, 27.1, 25.4, 22.1; IR $\left(\mathrm{CHCl}_{3}\right): v=1722 \mathrm{~cm}^{-1}$; HRMS (ESI): $m / z$ calcd for $\mathrm{C}_{28} \mathrm{H}_{32} \mathrm{O}_{6}+\mathrm{Na}^{+}$: 
$487.2091\left[\mathrm{M}^{\mathrm{Na}}{ }^{+}\right]$; found: 487.2091; elemental analysis calcd (\%) for $\mathrm{C}_{28} \mathrm{H}_{32} \mathrm{O}_{6}$ : C 72.39, H 6.94; found: C 72.18, H 7.10.

(4aR,9bS)-9b-Methyl 4a-[(1R,2S,5R)-5-methyl-2-(2-phenylpropan-2yl)cyclohexyl] 6-methoxy-1,4,4a,9b-tetrahydrodibenzo $[b, d]$ furan-4a,9bdicarboxylate (33). A solution of $\mathrm{Me}_{3} \mathrm{SnLi}(0.29 \mathrm{mmol})$ in $\mathrm{THF}(1,4 \mathrm{~mL})$ was treated with a solution of $\mathbf{3 2}(65 \mathrm{mg}, 0.14 \mathrm{mmol})$ in THF $(1.4 \mathrm{~mL})$ at $78^{\circ} \mathrm{C}$. After stirring for $1 \mathrm{~h}$, a solution of cis-1,4-bis(methylsulfonyloxy)-2butene $^{[35]}(42 \mathrm{mg}, 0.17 \mathrm{mmol})$ in DMF $(0.75 \mathrm{~mL})$ was added dropwise, and the reaction mixture was then stirred for 1 day at $-55^{\circ} \mathrm{C}$. The reaction mixture was quenched with deoxygenated $\mathrm{pH} 5.6$ acetate buffer, and partitioned between $\mathrm{CH}_{2} \mathrm{Cl}_{2}$ and acetate buffer. The aqueous phase was extracted with $\mathrm{CH}_{2} \mathrm{Cl}_{2}$ and the combined organic phase was washed with water and brine, dried, and concentrated. The crude product was purified by flash column chromatography (EtOAc/tol 1:50) to give $\mathbf{3 3}$ (36 mg, 50\%) as a pale yellow foam: ${ }^{1} \mathrm{H}$ NMR ( $500 \mathrm{MHz}, \mathrm{CD}_{2} \mathrm{Cl}_{2}$ ): $\delta=7.30(\mathrm{~m}, 4 \mathrm{H}), 7.15$ $(\mathrm{m}, 1 \mathrm{H}), 6.83(\mathrm{t}, J=7.8 \mathrm{~Hz}, 1 \mathrm{H}), 6.74(\mathrm{~m}, 2 \mathrm{H}), 5.83(\mathrm{~m}, 2 \mathrm{H}), 4.87(\mathrm{td}, J=$ $10.6,4.2 \mathrm{~Hz}, 1 \mathrm{H}), 3.82(\mathrm{~s}, 3 \mathrm{H}), 3.62(\mathrm{~s}, 3 \mathrm{H}), 2.78(\mathrm{~m}, 2 \mathrm{H}), 2.65(\mathrm{dd}, J=$ $16.2,5.8 \mathrm{~Hz}, 1 \mathrm{H}), 2.49(\mathrm{~d}, J=16.6 \mathrm{~Hz}, 1 \mathrm{H}), 2.05(\mathrm{~m}, 2 \mathrm{H}), 1.47(\mathrm{~m}, 2 \mathrm{H})$, $1.36(\mathrm{~s}, 3 \mathrm{H}), 1.26(\mathrm{~s}, 3 \mathrm{H}), 1.24(\mathrm{~m}, 1 \mathrm{H}), 1.07(\mathrm{dd}, J=23.2,11.7 \mathrm{~Hz}, 1 \mathrm{H})$, $0.95(\mathrm{~m}, 1 \mathrm{H}), 0.88(\mathrm{~d}, J=6.3 \mathrm{~Hz}, 3 \mathrm{H}), 0.78(\mathrm{ddd}, J=14.9,12.5,2.9 \mathrm{~Hz}$, $1 \mathrm{H}) ;{ }^{13} \mathrm{C}$ NMR $\left(62.9 \mathrm{MHz}, \mathrm{CD}_{2} \mathrm{Cl}_{2}\right): \delta=173.3,171.4,151.3,148.3,144.8$, 131.7, 128.6, 127.8, 126.3, 125.9, 125.8, 122.2, 115.8, 112.8, 94.2, 77.7, $60.8,56.4,52.9,50.9,41.6,40.9,34.9,34.7,32.5,31.9,31.0,28.0,23.1$, 22.1; IR (KBr): $v=1741,1727 \mathrm{~cm}^{-1}$; elemental analysis calcd (\%) for $\mathrm{C}_{32} \mathrm{H}_{38} \mathrm{O}_{6}$ : C 74.11, H 7.39; found: C 74.22, H 7.67.

((4aR,9bR)-6-Methoxy-1,4,4a,9b-tetrahydrodibenzo[b,d]furan-4a,9bdiyl)dimethanol (34). A suspension of $\mathrm{LiAlH}_{4}(60 \mathrm{mg}, 1.6 \mathrm{mmol})$ in THF $(1 \mathrm{~mL})$ was treated with a solution of $\mathbf{3 3}(330 \mathrm{mg}, 0.64 \mathrm{mmol})$ in THF (1.1 $\mathrm{mL})$ at $0{ }^{\circ} \mathrm{C}$. After being stirred for $3 \mathrm{~h}$ at $0{ }^{\circ} \mathrm{C}$, EtOAc $(1 \mathrm{~mL})$ was carefully added, followed by $\mathrm{CHCl}_{3}$, saturated aqueous $\mathrm{Na}_{2} \mathrm{CO}_{3}$, solid $\mathrm{KH}_{2} \mathrm{PO}_{4}$ and $\mathrm{Na}_{2} \mathrm{SO}_{4}$. The resulting suspension was stirred at r.t. for $1 \mathrm{~h}$, then filtered over celite and evaporated. The residue was chromatographed through a short column of $\mathrm{SiO}_{2}\left(4 \% i \mathrm{PrOH}-\mathrm{CH}_{2} \mathrm{Cl}_{2}\right)$ to give 34 in $75 \%$ yield $(126 \mathrm{mg})$ as a colorless oil: ${ }^{1} \mathrm{H}$ NMR $\left(250 \mathrm{MHz}, \mathrm{CDCl}_{3}\right): \delta=6.81(\mathrm{~m}, 1 \mathrm{H}), 6.68(\mathrm{~m}$, $1 \mathrm{H}), 6.60(\mathrm{dd}, J=7.4,1.0 \mathrm{~Hz}, 1 \mathrm{H}), 5.78(\mathrm{~m}, 2 \mathrm{H}), 4.05-3.57(\mathrm{~m}, 9 \mathrm{H}), 2.61-$ $2.24(\mathrm{~m}, 4 \mathrm{H}) ;{ }^{13} \mathrm{C} \mathrm{NMR}\left(62.9 \mathrm{MHz}, \mathrm{CDCl}_{3}\right): \delta=146.9,143.9,133.4,127.2$, 126.0, 121.3, 115.1, 111.1, 94.0, 66.5, 65.6, 55.6, 54.2, 32.9, 32.2; HRMS (ESI): $m / z$ calcd for $\mathrm{C}_{15} \mathrm{H}_{18} \mathrm{O}_{4}+\mathrm{Na}^{+}: 285.1097\left[M+\mathrm{Na}^{+}\right]$; found: 285.1100 . $\left(2 R, 2^{\prime} R\right)-((4 \mathrm{a} R, 9 \mathrm{~b} R)-6-$ methoxy-1,4,4a,9b-

tetrahydrodibenzo[b,d]furan-4a,9b-diyl)bis(methylene) bis(2-methoxy2-phenylacetate) (35). A solution of $\mathbf{3 4}(61 \mathrm{mg}, 0.23 \mathrm{mmol})$ in 1,2 dichloroethane $(0.6 \mathrm{~mL})$ was added to a solution of $(R)$ methoxyphenylacetic acid [(R)-MPA] ( $85 \mathrm{mg}, 0.51 \mathrm{mmol})$, DPC $(105 \mathrm{mg}$, $0.49 \mathrm{mmol})$ and DMAP $(8.5 \mathrm{mg}, 0.07 \mathrm{mmol})$ in 1,2-dichloroethane $(0.65$ $\mathrm{mL}$ ). The reaction mixture was stirred for 1 day at $40^{\circ} \mathrm{C} . \mathrm{H}_{2} \mathrm{O}$ was added, the layers were separated, and the aqueous phase was extracted with $\mathrm{CH}_{2} \mathrm{Cl}_{2}$. The combined organic layer was washed with $\mathrm{H}_{2} \mathrm{O}$ and brine, dried, and concentrated. The crude product was purified by column chromatography $\left(\mathrm{SiO}_{2}, \mathrm{CH}_{2} \mathrm{Cl}_{2}\right)$ to give $\mathbf{3 5}(113 \mathrm{mg}, 87 \%)$ as a colorless foam: $[\alpha]^{24}-57.2(0.5, \mathrm{MeOH}) ;{ }^{1} \mathrm{H}$ NMR $\left(500 \mathrm{MHz}, \mathrm{CD}_{2} \mathrm{Cl}_{2}\right): \delta=7.32$ (m, 10H), $6.72(\mathrm{~m}, 2 \mathrm{H}), 6.50(\mathrm{dd}, J=7.2,1.5 \mathrm{~Hz}, 1 \mathrm{H}), 5.63(\mathrm{~m}, 2 \mathrm{H}), 4.76$ (s, 1H), $4.68(\mathrm{~s}, 1 \mathrm{H}), 4.36(\mathrm{~d}, J=11.8 \mathrm{~Hz}, 1 \mathrm{H}), 4.28(\mathrm{~d}, J=11.8 \mathrm{~Hz}, 1 \mathrm{H})$, $4.24(\mathrm{~d}, J=11.6 \mathrm{~Hz}, 1 \mathrm{H}), 4.19$ (d, $J=11.6 \mathrm{~Hz}, 1 \mathrm{H}), 3.77$ (s, 3H), 3.36 (s, $3 \mathrm{H}), 3.33(\mathrm{~s}, 3 \mathrm{H}), 2.33(\mathrm{dd}, J=15.9,5.6 \mathrm{~Hz}, 1 \mathrm{H}), 2.20(\mathrm{dd}, J=15.7,5.8 \mathrm{~Hz}$, $1 \mathrm{H}), 1.98(\mathrm{~m}, 1 \mathrm{H}), 1.89(\mathrm{~m}, 1 \mathrm{H}) ;{ }^{13} \mathrm{C} \mathrm{NMR}\left(250 \mathrm{MHz}, \mathrm{CD}_{2} \mathrm{Cl}_{2}\right): \delta=170.6$, $170.5,147.5,144.6,136.85,136.83,132.6,129.3,129.2,129.1,127.74$, $127.67,126.2,121.8,115.7,112.5,91.8,83.0,82.9,67.4,67.2,57.84$, $57.80,56.2,52.7,32.9,32.0$; IR (KBr): $v=1753 \mathrm{~cm}^{-1}$; elemental analysis calcd (\%) for $\mathrm{C}_{33} \mathrm{H}_{34} \mathrm{O}_{8}: \mathrm{C} 70.95, \mathrm{H}$ 6.13; found: C 70.58, H 6.42 . (2S,2'S)-((4aR,9bR)-6-methoxy-1,4,4a,9b-tetrahydrodibenzo[b,d]furan4a,9b-diyl)bis(methylene)bis(2-methoxy-2-phenylacetate) (36). Following the same procedure as above, but using (S)-MPA (91 mg, 0.55 $\mathrm{mmol}), 65 \mathrm{mg}$ of $\mathbf{3 4}(0.25 \mathrm{mmol})$ gave $\mathbf{3 5}(100 \mathrm{mg}, 72 \%$ ) as a colorless foam: $[\alpha]^{20}{ }_{\mathrm{D}}=+28(c=0.5, \mathrm{MeOH}) ;{ }^{1} \mathrm{H} \mathrm{NMR}\left(500 \mathrm{MHz}, \mathrm{CD}_{2} \mathrm{Cl}_{2}\right): \delta=$ $7.28(\mathrm{~m}, 10 \mathrm{H}), 6.78(\mathrm{dd}, J=8.0,7.6 \mathrm{~Hz}, 1 \mathrm{H}), 6.72(\mathrm{dd}, J=8.1,1.2 \mathrm{~Hz}, 1 \mathrm{H})$, $6.56(\mathrm{dd}, J=7.5,1.2 \mathrm{~Hz}, 1 \mathrm{H}), 5.72(\mathrm{~m}, 2 \mathrm{H}), 4.70(\mathrm{~s}, 1 \mathrm{H}), 4.60(\mathrm{~s}, 1 \mathrm{H}), 4.27$ $(\mathrm{d}, J=11.8 \mathrm{~Hz}, 1 \mathrm{H}), 4.18(\mathrm{~d}, J=11.6 \mathrm{~Hz}, 1 \mathrm{H}), 4.16(\mathrm{~d}, J=11.6 \mathrm{~Hz}, 1 \mathrm{H})$, 4.01 (d, $J=11.8 \mathrm{~Hz}, 1 \mathrm{H}), 3.77$ (s, 3H), 3.34 (s, 3H), 3.33 (s, 3H), 2.41 (dd, $J=15.9,5.9 \mathrm{~Hz}, 1 \mathrm{H}), 2.18(\mathrm{~m}, 2 \mathrm{H}), 2.00(\mathrm{~m}, 1 \mathrm{H}) ;{ }^{13} \mathrm{C} \mathrm{NMR}(250 \mathrm{MHz}$, $\mathrm{CD}_{2} \mathrm{Cl}_{2}$ ): $\delta=170.5,170.3,147.7,144.4,136.73,136.69,133.0 .129 .2$, $129.14,129.10,129.07,127.7,127.63,127.58,126.3,121.7,115.7,112.5$, 91.9, 82.9, 67.7, 67.1, 57.8, 56.3, 52.4, 33.5, 32.2; IR (KBr): $v=1754 \mathrm{~cm}^{-1}$; elemental analysis calcd (\%) for $\mathrm{C}_{33} \mathrm{H}_{34} \mathrm{O}_{8}$ : C 70.95, H 6.13; found: C 71.22, H 6.28 .

Supporting Information (see footnote on the first page of this article): General experimental methods and copies of the ${ }^{1} \mathrm{H}$ and ${ }^{13} \mathrm{C}$ NMR spectra for all new compounds.

\section{Acknowledgments}

Financial support from Spanish MCYT (fellowship to A. V.) and Xunta de Galicia (Grants 10PXIB209113PR and 10PXIB209155PR) is gratefully acknowledged.

[1] a) F. López-Ortiz, M. J. Iglesias, I. Fernández, C. M. AndújarSánchez, G. Ruiz-Gómez, Chem. Rev. 2007, 107, 1580-1691, and references therein; b) S. P. Roche, J. A. Porco, Jr., Angew. Chem. Int. Ed. 2011, 50, 4068-4093.

[2] a) F. Ding, M. T. Valahovic, J. M. Keane, M. R. Anstey, M. Sabat, C. O. Trindle, W. D. Harman, J. Org. Chem. 2004, 69, 2257-2267; b) S. Dong, J. Zhu, J. A. Porco, Jr., J. Am. Chem. Soc. 2008, 130, $2738-$ 2739; c) J. Liang, J. Chen, J. Liu, L. Li, H. Zhang, Chem. Commun. 2010, 46, 3666-3668; d) J. Qi, A. B. Beeler, Q. Zhang, J. A. Porco, Jr., J. Am. Chem. Soc. 2010, 132, 13642-13644, and references therein; e) M. A. Lovchik, A. Goeke, G. Fráter, Tetrahedron: Asymmetry 2006, 17, 1693-1699; f) J. García-Fortanet, F. Kessler, S. L. Buchwald, J. Am. Chem. Soc. 2009, 131, 6676-6677.

[3] a) H. Brice, J. Clayden, Chem. Commun. 2009, 1964-1966; b) J. Clayden, S. Parris, N. Cabedo, A. H. Payne, Angew. Chem. Int. Ed. 2008, 47, 5060-5062; c) S. Lu, Z. Xu, M. Bao, Y. Yamamoto, Angew. Chem. Int. Ed. 2008, 47, 4366-4369; d) G. Ruiz-Gómez, A Francesch, M. J. Iglesias, F. López-Ortiz, C. Cuevas, M. SerranoRuiz, Org. Lett. 2008, 10, 3981-3984; e) G. Ruiz-Gómez, M. J. Iglesias, M. Serrano-Ruiz, F. López-Ortiz, J. Org. Chem. 2007, 72, 9704-9712; f) G. Barbe, G. Pelletier, A. B. Charette, Org. Lett. 2009, 11,3398-3401; g) J. Clayden, M. N. Kenworthy, M. Helliwell, Org. Lett. 2003, 5, 831-834; h) T. Bach, Angew. Chem. Int. Ed. 1996, 35, 729-730; i) I. Fernández, A. Forcén-Acebal, S. García-Granda, F. López-Ortiz, J. Org. Chem. 2003, 68, 4472-4485.

[4] a) T. Dohi, A. Maruyama, N. Takenaga, K. Senami, Y. Minamitsuji, H. Fujioka, S. B. Caemmerer, Y. Kita, Angew. Chem. Int. Ed. 2008, 47, 3787-3790; b) N. T. Vo, R. D. M. Pace, F. O'Hara, M. J. Gaunt, J. Am. Chem. Soc. 2008, 130, 404-405; c) S. Quideau, G. Lyvinec, M. Marguerit, K. Bathany, A. Ozanne-Beaudenon, T. Buffeteau, D. Cavagnat, A. Chénedé, Angew. Chem. Int. Ed. 2009, 48, 4605-4609; d) L. Pouységu, S. Chassaing, D. Dejugnac, A.-M. Lamidey, K. Miqueu, J.-M. Sotiropoulos, S. Quideau, Angew. Chem. Int. Ed. 2008, 47, 3552-3555; e) J. Liang, J. Chen, F. Du, X. Zeng, L. Li, H. Zhang, Org. Lett. 2009, 11, 2820-2823; f) J. Zhu, N. P. Grigoriadis, J. P. Lee, J. A. Porco, Jr., J. Am. Chem. Soc. 2005, 127, 9342-9343; g) Q. Liu, T. Rovis, Org. Process Res. Dev. 2007, 11, 598-604; h) L. H. Mejorado, T. R. R. Pettus, J. Am. Chem. Soc. 2006, 128, $15625-$ 15631 ; i) S. P. Cook, A. Polara, S. J. Danishefsky, J. Am. Chem. Soc. 2006, 128, 16440-16441.

[5] a) A. G. Schultz, Chem. Commun. 1999, 1263-1271; b) T. J. Donohoe, G. C. Freestone, C. E. Headley, C. L. Rigby, R. P. C. Cousins, G. Bhalay, Org. Lett. 2004, 6, 3055-3058; c) T. J. Donohoe, D. J. Johnson, L. H. Mace, R. E. Thomas, J. Y. K. Chiu, J. S. Rodrigues, R. G. Compton, C. E. Banks, P. Tomcik, M. J. Bamford, O. Ichihara, Org. Biomol. Chem. 2006, 4, 1071-1084; d) H. Pérez, C. Melero, A. Guijarro, M. Yus, Tetrahedron 2009, 65, 10769-10783; e) T. Kumamoto, K. Hosoya, S. Kanzaki, K. Masuko, M. Watanabe, K. Shirai, Bull. Chem. Soc. Jpn. 1986, 59, 3097-3101; f) A. G. 
Schultz, A. Wang, J. Org. Chem. 1996, 61, 4857-4859; g) R. Lebeuf, F. Robert, Y. Landais, Org. Lett. 2005, 7, 4557-4560.

[6] a) A. R. Pape, K. P. Kaliappan, E. P. Kündig, Chem. Rev. 2000, 100, 2917-2940; b) F. C. Pigge, J. J. Coniglio, R. Dalvi, J. Am. Chem. Soc. 2006, 128, 3498-3499; c) P. L. Smith, M. D. Chordia, W. D. Harman, Tetrahedron 2001, 57, 8203-8225; d) E. P. Kündig, A Bellido, K. P. Kaliappan, A. R. Pape, S. Radix, Org. Biomol. Chem. 2006, 4, 342-351; e) A. Quattropani, G. Anderson, G. Bernardinelli, E. P. Kündig, J. Am. Chem. Soc. 1997, 119, 4773-4774; f) J. Barluenga, A. A. Trabanco, J. Flórez, S. García-Granda, E. Martín, J. Am. Chem. Soc. 1996, 118, 13099-13100.

[7] a) N. Chopin, H. Gérard, I. Chataigner, S. R. Piettre, J. Org. Chem. 2009, 74, 1237-1246; b) J. E. Camp, D. Craig, Tetrahedron Lett. 2009, 50, 3503-3508.

[8] a) P. G. Cozzi, R. Hilgraf, N. Zimmermann, Eur. J. Org. Chem. 2007, 5969-5994; b) B. M. Trost, C. Jiang, Synthesis 2006, 369-396; c) J. Christoffers, A. Baro, Quaternary Stereocenters: Challenges and Solutions for Organic Synthesis, Wiley-VCH, Weinheim, 2005.

[9] a) T. J. Donohoe, A. J. McRiner, M. Helliwell, P. Sheldrake, J. Chem. Soc., Perkin Trans. 1, 2001, 1435-1445; b) T. J. Donohoe, A. J. McRiner, P. Sheldrake, Org. Lett. 2000, 2, 3861-3863.

[10] P. Monje, P. Graña, M. R. Paleo, F. J. Sardina, Org. Lett. 2006, 8, 951-954.

[11] M. R. Paleo, M. I. Calaza, P. Graña, F. J. Sardina, Org. Lett. 2004, 6, 1061-1063.

[12] J. A. Joule, K. Mills, Heterocyclic Chemistry, 4th ed, Blackwell Science, Oxford, 2004, Ch 15

[13] P. A. Caruana, A. J. Frontier, Tetrahedron 2004, 60, 10921-10926.

[14] D. Crich, M. Patel, Org. Lett. 2005, 7, 3625-3628.

[15] J. Barluenga, S. K. Nandy, Y. R. S. Laxmi, J. R. Suárez, I. Merino, J. Flórez, S. García-Granda, J. Montejo-Bernardo, Chem. Eur. J. 2003 9, 5725-5736, and references therein.

[16] a) H. Chen, R. Liu, W. H. Myers, W. D. Harman, J. Am. Chem. Soc. 1998, 120, 509-520; b) Y. Ohta, M. Doe, Y. Morimoto, T. Kinoshita J. Heterocycl. Chem. 2000, 37, 751-755.

[17] J. P. Dumas, S. J. Boyer, J. A. Dixon, T. K. Joe, H. C. E. Kluender, W. Lee, D. Nagarathnam, R. N. Sibley, N. Su, U.S. Patent 6689883 , 2004.

[18] Isopropyl and ethyl esters were found to give better results in the stanna-Brook rearrangement/bis-alkylation procedure than methyl or tert-butyl esters. We attribute this behavior to a balance between hindrance towards nucleophilic addition of the $\mathrm{R}_{3} \mathrm{SnLi}$ and leaving group ability of the $\mathrm{OR}$ group. $\mathrm{Bu}_{3} \mathrm{SnLi}$ can also be used for these transformations with only a slight decrease in yield due to the fact that the $n$-butyltin byproducts are harder to remove from the final products. See reference 10 .

[19] a) Diethyl thiophene-2,3-dicarboxylate: K.-Y. Tserng, L. Bauer, $J$. Org. Chem. 1975, 40, 172-175; b) Thiophene-2,3-dicarboxylic acid: K. Hammer, T. Benneche, H. Hope, K. Undheim, Acta Chem. Scand. 1997, 51, 392-402.

[20] A. S. Kyei, K. Tchabanenko, J. E. Baldwin, R. M. Adlington, Tetrahedron Lett. 2004, 45, 8931-8934.
[21] CCDC-845741 (for 16c) and -845740 (for 25e) contain the supplementary crystallographic data for this paper. These data can be obtained free of charge from The Cambridge Crystallographic Data Centre via www.ccdc.cam.uk/data_request/cif.

[22] a) E. V. Panteleeva, T. A. Vaganova, E. A. Lukyanets, V. D Shteingarts, Russ. J. Org. Chem. 2006, 42, 1280-1288; b) E. V. Panteleeva, M. Y. Lukyanova, L. M. Pokrovsky, V. D. Shteingarts, Russ. Chem. Bull., Int. Ed. 2007, 56, 1110-1118.

[23] W. C. Still, J. Am. Chem. Soc. 1977, 99, 4836-4838.

[24] C. Tamborski, F. E. Ford, E. J. Soloski, J. Org. Chem. 1963, 28, 237-239.

[25] D. B. Berkowitz, J. M. McFadden, M. K. Sloss, J. Org. Chem. 2000, $65,2907-2918$.

[26] J. Marco-Contelles, M. C. Carreiras, C. Rodríguez, M. Villarroya, A G. García, Chem. Rev. 2006, 106, 116-133.

[27] 30 was prepared following the procedure for the synthesis of diethyl 7-methoxybenzofuran-2,3-dicarboxylate, but using methyl bromoacetate and dimethyl oxalate instead of the ethyl analogs, see: E. Ohshima, T. Kawakita, K. Yanagawa, K. Iida, R. Koike, Y Nakasato, T. Matsuzaki, K. Ohmori, S. Sato, H. Ishii, H. Manabe, M. Ichimura, F. Suzuki, U.S. Pat. Appl. 20020128290, 2002.

[28] B. M. Trost, J. L. Belletire, S. Godleski, P. G. McDougal, J. M. Balkovec, J. J. Baldwin, M. E. Christy, G. S. Ponticello, S. L. Varga, J. P. Springer, J. Org. Chem. 1986, 51, 2370-2374.

[29] R. E. Grote, E. R. Jarvo, Org. Lett. 2009, 11, 485-488.

[30] The solution was always kept cold during cannulation by using a $\mathrm{CO}_{2}$ jacket surrounding the cannula.

[31] a) X.-B. Wang, J. E. Dacres, X. Yang, K. M. Broadus, L. Lis, L.-S. Wang, S. R. Kass, J. Am. Chem. Soc. 2003, 125, 296-304; b) M. M. Faul, A. M. Ratz, K. A. Sullivan, W. G. Trankle, L. L. Winneroski, J. Org. Chem. 2001, 66, 5772-5782.

[32] F. A. Bottino, G. Di Pasquale, A. Pollicino, A. Recca, P. A. Staniland, J. Heterocyclic Chem. 1989, 26, 929-931.

[33] A. N. De Silva, C. L. Francis, A. D. Ward, Aust. J. Chem. 1993, 46, 1657-1671.

[34] M. C. Pumar, A. Mouriño, L. Castedo, An. Quim., Ser. C, 1988, 84, 105-111.

[35] Z. Ding, J. J. Tufariello, Synth. Commun. 1990, 20, 227-230.

Received: ((will be filled in by the editorial staff)) Published online: ((will be filled in by the editorial staff)) 
